Recibido: junio de 2016

Aprobado: agosto de 2016

DOI: https://doi.org/10.15332/rev.m.v14i0.2170

Ciudad dispersa. Periferia de Atlanta, EUA Fuente: Google Earth, 2012.

Artículo de investigación derivado de los estudios realizados con el Laboratorio de Ambiente Urbano y Edificado (Laurbe) vinculado al Programa de Posgrado en Arquitectura y Urbanismo (PPGAU), Departamento de Arquitectura, Centro de Tecnología (CT) de la Universidad Federal de Paraíba (UFPB). Publicado originalmente en Cadernos de Arquitetura e Urbanismo del PUC Minas (PUC MG, Brasil), vol. 23, n. 33, 2016. Recuperado de http://periodicos. pucminas.br/index.php/Arquiteturaeurbanismo/article/view/I5688

** Posdoctor por la Facultad de Arquitectura de la Universidad de Lisboa (2015-2016); doctor e investigador por la FAU-UnB (20I I); magíster en Geografía por la UFMTMT (2007); Arquitecto y urbanista por la UFU-MG (2003). Profesor de pregrado y posgrado en Arquitectura y Urbanismo (PPGAU), y de posgrado en Ingeniería Civil y Ambiental (PPGECAM) de la Universidad Federal da Paraíba - UFPB. Correo electrónico: galexarq@gmail.com

\section{CIUDADES COMPACTAS Y VERDES: DISCUSIONES SOBRE LA CALIDAD DE VIDA Y LA SOSTENIBILIDAD URBANA*}

\author{
Geovany Jessé Alexandre da Silva** - Universidade Federal da Paraíba, Brasil \\ José Augusto Ribeiro da Silveira*** - Universidade Federal da Paraíba, Brasil \\ Edson Leite Ribeiro**** - Ministério do Planejamento, Brasilia, D.F., Brasil
}

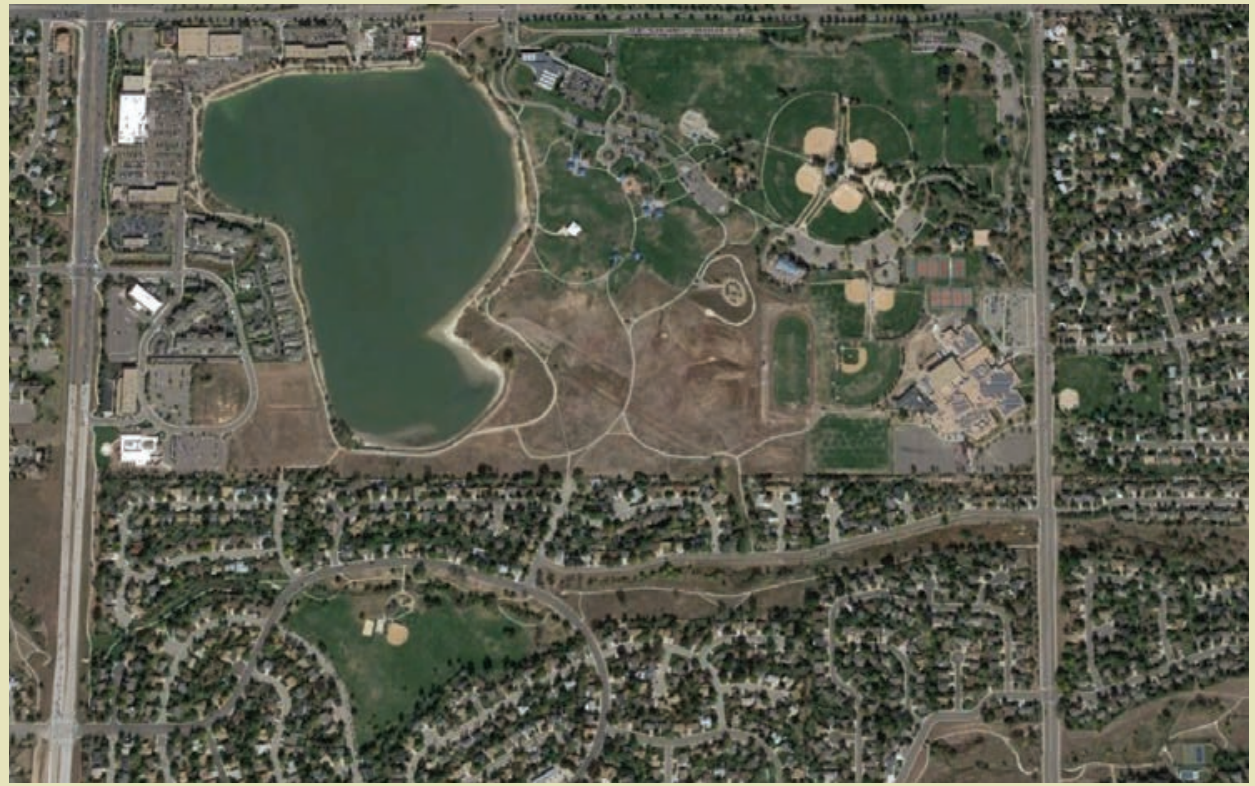

\section{RESUMEN}

El presente artículo hace un análisis de los aspectos positivos y negativos del modelo compacto, valiéndose de una comparación entre este y los principales planteamientos de la propuesta estadounidense denominada "smart growth" (crecimiento inteligente). El objetivo principal de la investigación fue explorar los dos modelos, estableciendo el impacto urbano que cada uno ha tenido sobre la naturaleza, el consumo de energía, el agotamiento de los espacios naturales y sobre la misma calidad de vida de los habitantes. En términos metodológicos, se tomaron como punto de partida algunas de las hipótesis que se han estructurado con base en la teoría disponible, así como ciertos índices de compactación urbana, utilizados internacionalmente. Mediante simulaciones se obtuvieron conclusiones relativas a la disponibilidad y accesibilidad de elementos cualitativos urbanos. Este método también permitió identificar la percepción que tiene la comunidad de dichos elementos. Los resultados obtenidos muestran que si bien en algunos casos los indicadores cuantitativos y cualitativos de un modelo urbano más expansivo pueden parecer mejores por la cantidad de espacio disponible (por ejemplo, áreas verdes), una aplicación más eficiente de estos se puede observar en un modelo más compacto, dado que es posible una mejor distribución de los espacios, correctamente dimensionados y oportunamente accesibles, para así optimizar su potencial de uso.

\section{PALABRAS CLAVE}

Ciudades compactas; ciudades verdes; expansión urbana; calidad de vida; sostenibilidad urbana. 


\section{CIDADES COMPACTAS E VERDES: DISCUSSÕES ACERCA DA QUALIDADE DE VIDA E SUSTENTABILIDADE URBANA}

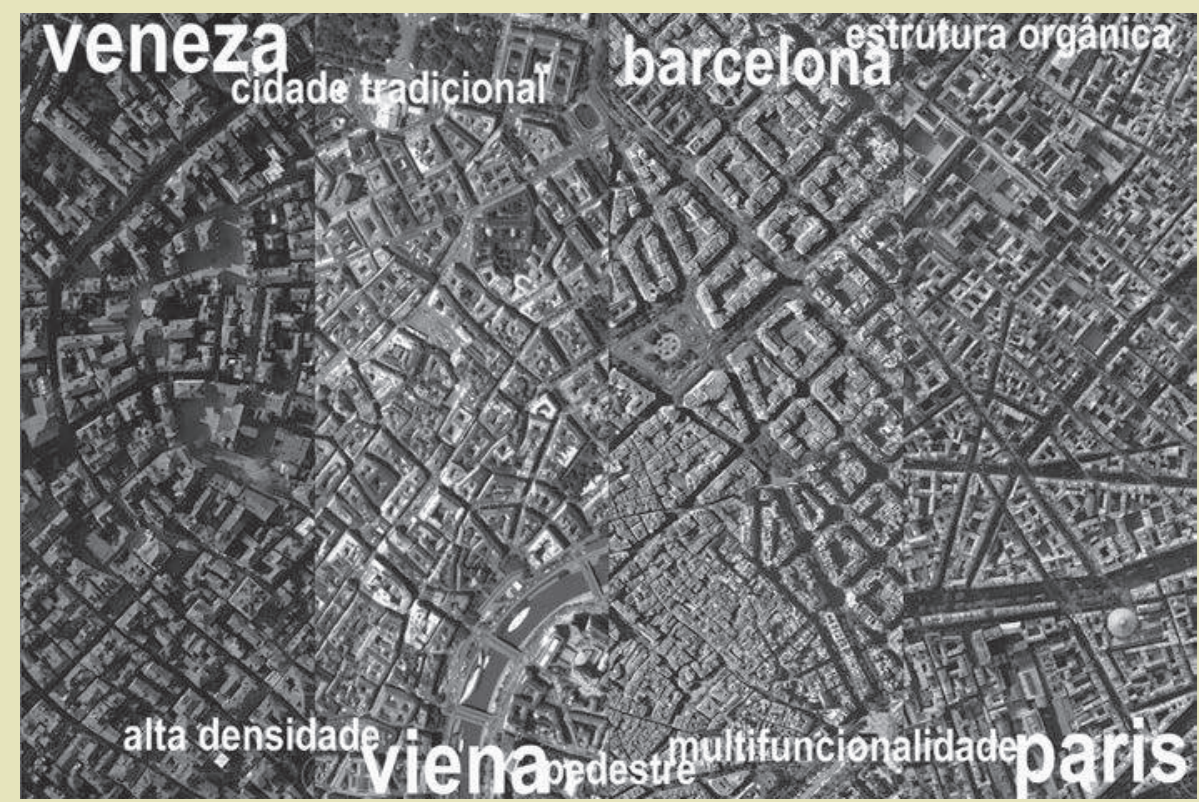

RESUMO

O presente estudo trata de uma análise dos aspetos positivos e negativos do modelo compacto, utilizando uma comparação com as premissas da proposta americana denominada "smart growth" (crescimento inteligente). O objetivo da pesquisa foi explorar os dois modelos, comparando a interferência dos impactos urbanos sobre a natureza, o consumo de energia, o esgotamento dos espaços naturais e a qualidade de vida dos habitantes. Em termos metodológicos, algumas das hipóteses estruturadas a partir da teoria disponível foram tomadas como ponto de partida e alguns índices de compactação urbana que são utilizados internacionalmente foram assumidos. Através de simulações, foram obtidas conclusões sobre disponibilidade e acessibilidade a elementos qualitativos urbanos. Da mesma forma, fomos à simulação da perceção desses elementos pela comunidade. $O$ resultado mostrou que, embora em alguns casos os indicadores quantitativos e qualitativos de um modelo urbano mais expansivo possam parecer melhores devido à quantidade disponível de espaços (por exemplo, áreas verdes), uma aplicação mais eficaz e eficiente destes pode ser verificada em mais compacto, graças à possibilidade de uma melhor distribuição espacial e de uma acessibilidade adequada, bem como a um dimensionamento mais adequado, em escala humana, otimizando seu potencial de uso.

\section{PALAVRAS-CHAVE}

Cidades compactas; cidades verdes; expansão; qualidade de vida; sustentabilidade urbana.
Ciudades de diseño tradicional y compacto en Europa Fuente: Elaboración Geovany J. A. Silva, 2013.
*** Doctor en Desarrollo Urbano por la CACUFPE; magíster en Desarrollo Urbano por la CAC-UFPE (MDU, 1997) y (MDU, 2004); título en Arquitectura y Urbanismo por la UFPB (CT, 1982); profesor pregrado y posgrado en Arquitectura y Urbanismo (PPGAU), y de posgrado en Ingeniería Civil y Ambiental (PPGECAM) de la Universidad Federal da Paraíba - UFPB. Correo electrónico: ct.laurbe@gmail.com

**** Posdoctor del Institut National des Sciences Appliquées - INSA- Lyon, 2008; doctorado en Ingeniería Civil por la USP (1991), magíster en Desarrollo Urbano por la UFPE (1988); título de pregrado en Arquitectura e Urbanismo por la Universidade Guarulhos (1978). Analista de Infraestrutura (Desarrollo Urbano) del Ministério do Planejamento, Brasília-DF. Correo electrónico: edlribeiro@gmail.com 


\section{INTRODUCCIÓN}

En las últimas décadas, la adhesión a la propuesta de la compactación urbana ha crecido significativamente entre los urbanistas del mundo, particularmente en la Europa continental, donde la sprawl urbana, aun habiendo ocurrido a un ritmo menor que en Estados Unidos y otras regiones del mundo, ha resultado problemático, en función del impacto altamente negativo provocado sobre el espacio rural y el entorno natural, incluyendo las culturas agrícolas tradicionales como los viñedos y sus actividades derivadas, siendo este un elemento importante de la cultura y de la economía rural de varios países del continente europeo. Por otro lado, la dependencia automotriz es otro factor relevante en dicho proceso; mientras que se produce un vasto territorio urbano de baja densidad (de unidades habitacionales unifamiliares) y de separación de usos, hay una disolución de la escala humana (peatonal) para acceder a las diferentes partes de la ciudad, distanciando la relación entre el habitar, el trabajo y el ocio - recreo, como consecuencia de la necesidad de circulación. Los otros factores pueden ser enumerados, como la segregación socio-espacial, encarecimiento de la infraestructura y mantenimiento de los sistemas urbanos, aislamiento de comunidades, poca cohesión social, alto grado de emisión de gases y mayor demanda de recursos, residuos y energías.

Muchos estudios preconizan la ciudad compacta como un modelo adecuado para la sostenibilidad urbana, aunque se debe considerar que esta hipótesis no es consensual. En parte, porque algunos estudios no lograron demostrar con claridad el buen desempeño ambiental o sostenible, en relación con la ciudad dispersa. Otros autores buscan una solución alternativa entre la sprawl y la ciudad compacta, proponiendo el smart growth. En esta última propuesta, se intenta presentar alternativas de composición entre estructuras urbanas dispersas, con asentamientos más nucleados y con posibilidades puntuales de reducción del uso de la circulación vehicular individual. La contradicción está en el hecho de que esas propuestas no dan una respuesta sistémica al funcionamiento de la ciudad como un todo, pero sí de forma fragmentada y presentando soluciones solo accesibles a través del mercado inmobiliario de lujo. Las estructuras resultantes parecen más un collage que un sistema coherente. En este ámbito están también las propuestas enmarcadas dentro del "nuevo urbanismo norteamericano", que aparentan cierta coherencia interna, pero representan solo simulaciones de un sistema espacial equilibrado, sin presentar buena sinergia sistémica con el resto de la ciudad. Sin embargo, es una propuesta de intensificación del uso urbano en un espacio de ciudad dispersa.

Entre los críticos de la ciudad compacta, uno de los argumentos más utilizados ha sido el de la supuesta baja calidad de vida urbana, provocada por la posible escasez de espacios abiertos y naturales en el espacio intraurbano. Hay quienes sostienen, por un lado, que en una ciudad compacta el ambiente sería más sofocante. Sin embargo, isería verdadera esta suposición?, icuál debería ser la dimensión ideal de los espacios libres y verdes urbanos?, ¿cuál sería la proporción ideal entre los espacios y volúmenes edificados y los espacios libres? Algunos afirman que aquella ciudad con una proporción mayor de espacios libres y verdes intraurbanos con respecto a otra sería siempre la mejor. ¿Sería esta una hipótesis comprobable?

Además, se debe tener en cuenta que la obsesión por grandes cantidades de espacios libres y verdes en repetidas ocasiones se piensa para la escala del automóvil y no para la escala humana o la de las funciones colectivas, de los vínculos comunitarios y de la cohesión social. En varios casos, sería más apropiado llamar a los "espacios públicos" como "distancias públicas", debido al dimensionamiento desproporcionado en la escala del peatón. Los ejes monumentales, los grandes separadores verdes en el centro de las autopistas, vías expresas, los extensos céspedes en los cruces o intersecciones de las carreteras, no son espacios 
utilizables por el peatón. Son áreas diseñadas a escala del automóvil para una circulación masiva y a alta velocidad. Por otro lado, el encuentro de las personas y las dinámicas de las interacciones humanas, de ocio y de cultura son muy distintas entre las ciudades compactas y dispersas, ya que en las primeras, el uso del espacio se ve intensificado, mientras que en las segundas, la superioridad de área verde per cápita termina por diseminar a la población en espacios públicos o núcleos aislados con una menor intensidad de uso.

Al observar algunas ciudades se notan las preferencias de permanencia de los peatones sobre los espacios libres, destacándose que: a) en la "ciudad modernista" (caso de Brasilia - Chandigarh), los espacios más densos en sectores comerciales tienen una permanencia humana mayor que la de los grandes ejes o en los grandes prados de los espacios monumentales o las vías axiales secundarias; $b$ ) en las ciudades europeas, los senderos peatonales - las calles con cafés y tiendas, así como las zonas centrales de origen medieval y de los siglos XVIII y XIX, son los lugares de reunión preferidos de los ciudadanos con relación a los ejes viales principales, diagonales y otros espacios de mayor velocidad automovilística; c) los pasillos de tiendas en los actuales centros comerciales reproducen, en la práctica, un espacio donde la gente se encuentra frecuentemente, quizá porque se evocan los espacios cálidos de las estrechas callejuelas peatonales de los centros urbanos tradicionales'. Sin embargo, en dichos centros comerciales, en este simulacro de concurridos espacios de otrora, se vive una realidad ficticia, simulada, escenográfica y bastante contradictoria.

Mientras en el escenario se simula un espacio íntimo y típico para peatones, en sus "bastidores", por el contrario, se puede observar un "mar" de estacionamientos, precisamente porque la estructura de funcionamiento de un centro comercial, a diferencia de lo que su apariencia escenográfica propone, fue hecha para el automóvil. Esta "nulidad real" puede ser vista como el aspecto más destacado de su característica de "no-lugar". El diseño de agrupaciones comerciales, a partir de una zonificación urbana monofuncional, es el resultado de la separación de las funciones urbanas en el territorio disperso, conectadas por vías, (des)integrando áreas urbanas de baja densidad con una acentuada movilidad automotriz individual. Las ciudades norteamericanas son ejemplos mundiales de este modelo urbano, como la ciudad de Atlanta, una de las más dispersas del mundo. La figura I muestra parte del diseño urbano de esta ciudad en 2012: en el área central comercial y de servicios (a la izquierda), repleto de vías y estacionamientos, y en el suburbio residencial (a la derecha), amplias viviendas y mucha área verde.

El diseño de barrios periféricos de baja densidad (alrededor de 10 hab/ha) induce a la dependencia automotriz individual, que lleva a una legislación inductora del automóvil y de los sistemas viales, en virtud de las necesidades de desplazamiento entre trabajo, casa y ocio, con un alto costo per cápita de urbanización y mantenimiento de los sistemas urbanos.

Aunque se viva sobre una verdadera apología al automóvil y en el círculo vicioso de la dependencia automotriz (transportes $x$ ocupación y uso del suelo / planificación urbana y regional), en el fondo, las preferencias inconscientes de las personas todavía son los espacios peatonales y los espacios dedicados a los encuentros sociales, no motorizados. La preferencia innegable de la sociedad aún es el lugar pleno de significados sociales y culturales, contrario al "no-lugar", que solo lleno de signos, tal como se menciona en un manifiesto de Milano-Lab, 2005:

De hecho, distinto en relación a los espacios públicos tradicionales, incluso en su área escenográfica, está el foco centralizado en un solo verbo: consumir, en vez de ser espacios donde el "encontrarse" y el "relacionarse" o "convivir" sean sus características más importantes. La propia función de mercado, cargada de profundo sentido de relación social (de intercambios), pierde el carácter de estos elementos, en el funcionamiento del comercio globalizado y automatizado del mercado contemporáneo. 
Figura I. Diseño urbano disperso de Atlanta EE.UU. (20I2), a la izquierda, un área central de autopistas y grandes estacionamientos $y, a$ la derecha, una superficie habitacional periférica con baja densidad de población

Fuente: Adaptación de los autores con base en Google Earth (2012)
Figura 2. Relación entre longitud de carretera por persona y kilómetro recorrido por pasajeros para algunas regiones y países en 2003

Fuente: Silva (20II) UN-Habitat (2008, p. I76) / Kenworthy, 2003
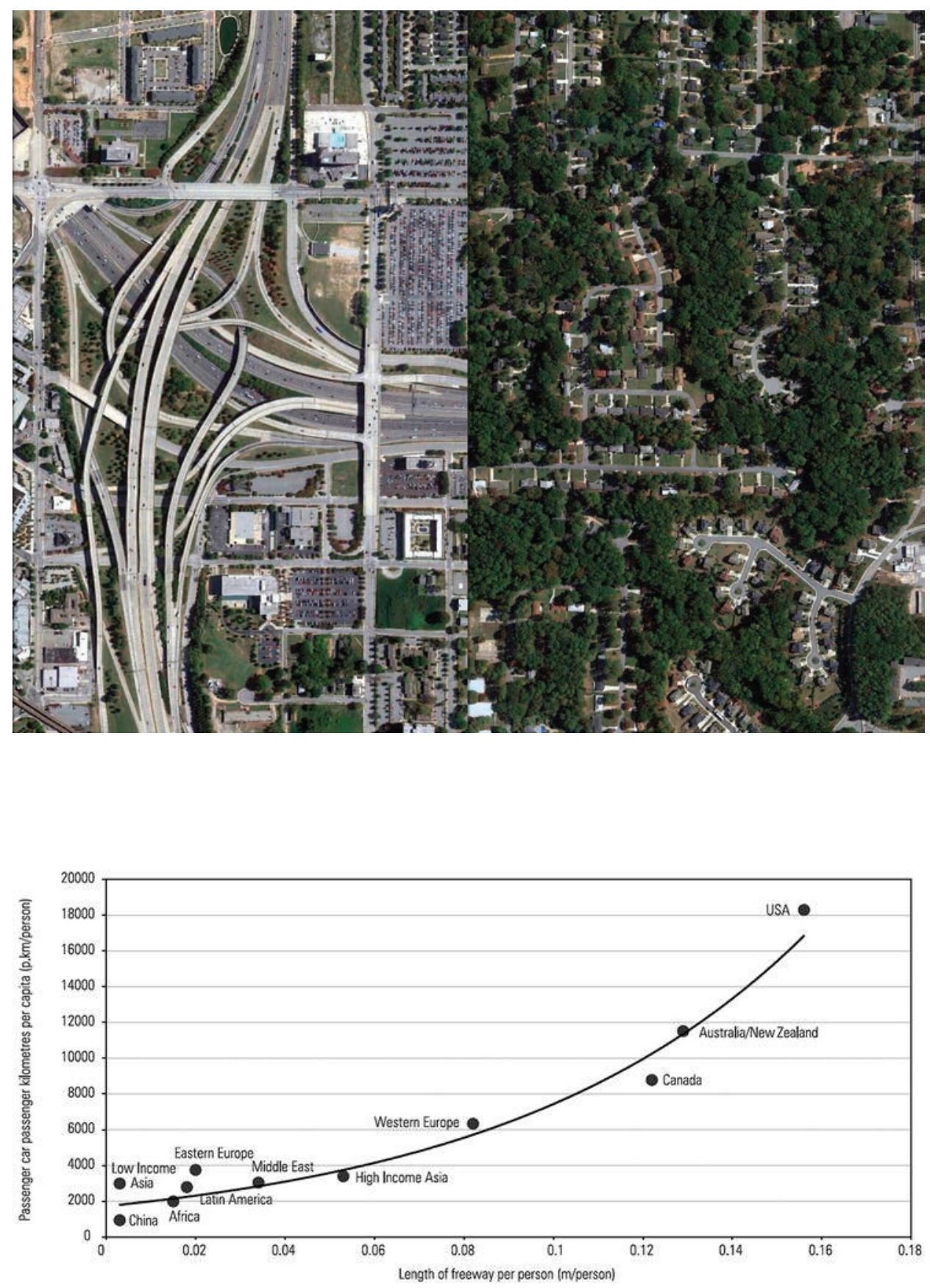

Source: Adapted from: Kenworthy 2003

(...) necesitamos habituarnos a proyectar ante todo los espacios de las relaciones humanas y restarle prioridad a los espacios físicos. El proyecto de los espacios físicos representa una consecuencia o condición, puede influir o valorizar un proyecto pero, ante todo, es necesario proyectar para el modo, el sentido y el objetivo con el que las personas viven, individualmente y en sociedad [Sic] (Medeiros, Mangueira, Silva, Silveira, 20 I6, p. I7).

En ese sentido, la adopción de modelos urbanos, estructurales y dimensionales, que permitan esa prioridad del espacio de permanencia y de relación humana sobre los demás es urgente, tanto para la calidad de vida como para la sostenibilidad. 
Como principio, se toma el concepto de la ciudad como un sistema urbano y como un sistema espacial. Así bien, se consideraría como sistema espacial el "grupo de elementos interconectados y organizados de manera que funcionen en conjunto, buscando la optimización de intercambios y de flujos, de relaciones, de informaciones, de energía y materia”2.

Para el concepto de sistema urbano, se puede adoptar lo siguiente: "sistema espacial organizado para optimizar la calidad de vida y la prestación de servicios a la población". En la misma línea de conceptualización, si fuésemos a cualificar el sistema urbano de un ecosistema urbano equilibrado o relativo a una ciudad sostenible, podríamos añadir al anterior concepto la siguiente extensión: “(...) calidad de vida y la prestación de servicios a la población de forma igualitaria para las generaciones presentes y futuras (intra-generacional e intergeneracional)”.

Por lo tanto, dentro del sistema urbano, así como dentro del origen histórico de la ciudad, a pesar de todas las contradicciones generadas a través del tiempo por diferentes formas de explotación, queda evidenciada su condición colectiva y social. Una gran contradicción existente en la forma de "resolver" las cuestiones intraurbanas contemporáneas es su carácter particular, específico, individual, parcial y no colectivo. Esta contradicción hace que la ciudad se convierta en un "collage" no sistémico, donde sus elementos no interactúan ni se integran. La fragmentación de espacios en virtud de intereses especulativos, áreas nobles (gentrificación), conduce a invasiones no reconocidas por la gestión urbana en las áreas periféricas, o incluso la obsolescencia y abandono de las áreas centrales más antiguas y devaluadas (debido, en parte, a las legislaciones patrimoniales). Este proceso puede ser verificado en diversos escenarios urbanos del mundo occidental.

\section{ALGUNOS PROCEDIMIENTOS METODOLÓGICOS ADOPTADOS EN EL ANÁLISIS DE LA DISPERSIÓN ESPACIAL URBANA}

En términos de procedimientos metodológicos para el análisis espacial de ciudades, se adoptaron como punto de partida las hipótesis estructuradas a partir de la teoría disponible. De la misma manera, se asumieron algunos índices de compactación urbana que se utilizan internacionalmente.

A partir de estos resultados y configuraciones, se buscó evaluarlos comparativamente, por medio de la utilización de simulaciones de potencialidades para los modelos más compactos, los modelos más dispersos y otros más cercanos al concepto de smart growth. De esta comparación se obtuvieron conclusiones sobre la disponibilidad y la accesibilidad a elementos cualitativos urbanos, como también sobre su percepción y potencial de utilización por parte de la colectividad.

En general, la dispersión urbana no se mide solo por su extensión superficial. De acuerdo con Maignant (2004), además de la relación entre su extensión superficial y su densidad demográfica y construida, se utilizan tres indicadores básicos de su característica bidimensional: a) la relación entre superficie urbana/perímetro urbano; b) la relación entre la superficie de la ciudad y la superficie de un círculo circunscrito teórico, y c) la relación entre un círculo teórico inscrito y un círculo teórico circunscrito. Entre los índices básicos más utilizados están los índices de Gravélius (1914), Miller (1953) y Morton (2003) (Maignant, 2004), que se indican a continuación:

2 De hecho, el origen de la Teoría General de los Sistemas, propuesta por Von Bertalanffy (1950 y 1968), tiene su origen en el funcionamiento orgánico interno de seres vivos y en su extrapolación hacia organismos compuestos, donde la importancia del funcionamiento conjunto del organismo se consideraba superior al funcionamiento individual de cada órgano o parte aislada. De esta manera, en el sistema urbano, el collage de pequeñas partes que funcionan bien internamente, pero no se relacionan bien en el conjunto, no son capaces de agregar calidad a su funcionamiento. 
Tabla I. Índices básicos utilizados para el análisis de la dispersión urbana

\begin{tabular}{|c|c|c|}
\hline Índice de Miller & Índice de Morton & Índice de Gravélius \\
\hline I Miller $=\frac{4 \Pi \cdot S}{P^{2}}$ & IMorton $=\frac{S}{\Pi(0,5 \cdot T)^{2}}$ & IGravélius $=\frac{P}{2 \sqrt{\Pi \cdot S}}$ \\
\hline
\end{tabular}

Donde: $S=$ Superficie (área); $P$ = Perímetro urbano; $T$ = Índice de dispersión, es decir, la mayor dimensión entre todas las direcciones. Fuente: Elaboración autores.

Por tanto, no se trata solamente de una cuestión cuantitativa (área superficial), sino también de configuración, composición, proporción o morfología espacial, además de sus densidades. De esta forma, una ciudad con una gran superficie puede ser más compacta que un área urbana de menor extensión, siempre y cuando sus densidades y sus aspectos morfológicos definan estructuras menos dispersas o fragmentadas ${ }^{3}$.

\section{LA NECESIDAD DE UN FUNCIONAMIENTO SINÉRGICO Y ECOLÓGICO DE UN SISTEMA ESPACIAL URBANO SOSTENIBLE}

Ante lo evidenciado, el problema que parece inalcanzable o, al menos, inexplicable, se refiere al funcionamiento insostenible del espacio urbano, debido a la falta de una sinergia sistémica en el funcionamiento de la ciudad. Un sistema, por definición, debe ser un conjunto de elementos que, aun funcionando diferente entre sí, trabajen en conjunto y de forma armónica. Así, un sistema espacial, entre los que también se enmarca el sistema urbano, debería funcionar a partir de un sistema armónico y eficiente. En la gestión del tiempo y del espacio, dentro del sistema urbano, dos cosas son absolutamente esenciales dentro de un sistema espacial: a) la mayor aproximación posible de la condición isotrópica plena, y, b) la mayor optimización posible de los espacios y de los dispositivos que permitan o faciliten su utilización para la calidad de vida de sus habitantes.

La eficiencia máxima de un sistema espacial urbano ocurre en el funcionamiento de la isotropía. Un sistema espacial isotrópico es aquel donde las condiciones de accesibilidad son (en condiciones de homogeneidad) igual a cada fase de la expansión espacial del sistema. En cierto modo, es un sistema que presenta una analogía bastante fuerte al modelo gravitacional. En este modelo, todos los grupos se mantienen equidistantes (isonomía espacial y de accesibilidades) al centro polarizador y proveedor de bienes y servicios. Evidentemente, una isonomía total en el plano físico y social (socioeconómico, cultural, físico-natural, físico-estructural urbano, etc.) que pueda conducir a una isotropía plena, es una hipótesis abstracta, mucho más teórica que práctica. Sin embargo, el principio presenta una coherencia espacial perfecta. Las "deformaciones" insertadas a partir de este modelo, permitidas por la diversidad cultural y social, por los condicionamientos de varias vertientes, como por ejemplo la fisiografía natural, el funcionamiento del sistema regional, etc., además de expresar la forma cultural propia de resolución del espacio, llevan a definir las potencialidades o las nuevas necesidades de cada sector, según el nivel de distanciamiento de la condición isotrópica. En general, las condiciones más cercanas a la isotropía permiten mucho más usos potenciales y menor dependencia a las soluciones espaciales que se alejan de esta.

3 En los tres índices, la mejor condición configuracional, que sería representada por el círculo, que demuestra la isotropía perfecta, tendría el índice I, considerado el más cercano al equilibrio. La única diferencia entre los índices es que mientras que los índices de Miller y Morton varían entre 0 (peor condición, donde la dispersión es mayor) y I (condición isotrópica perfecta), el índice de Gravélius es un índice negativo: el ideal es I, pero a medida que se aumenta la dispersión, se aumenta el valor del índice. 
En una condición isotrópica se facilita la no dependencia por los sistemas mecánicos o motorizados para la circulación, aunque a veces su dimensión lo exija, cuando las distancias a recorrer, incluso en la condición optimizada, se alejen de la escala espacio-temporal deseable para el desplazamiento a pie, dentro del ritmo de funcionamiento de la ciudad contemporánea. Además, el propio uso del sistema mecánico y motorizado, en una condición más isotrópica, también ocurre dentro de la condición optimizada, ya que las densidades son importantes para el funcionamiento de un sistema de atención colectiva, como el sistema de transporte público. Esta viabilidad es optimizada en ciudades más compactas, pues se atiende a un número mayor de personas por metro cuadrado de sistema de transporte colectivo, abaratando tales servicios.

Pero todavía hay ciudades totalmente apropiadas para el desplazamiento a pie, son, en general, ciudades de conformación medieval o con soluciones espaciales semejantes, con buena densidad y diversidad de ocupación y usos. Aunque esta situación urbana no es tan común en la actual realidad brasileña y en las ciudades del continente americano, algunos sectores urbanos podrían localmente establecer las condiciones para tal uso. La densidad de ocupación, la diversidad y la mezcla de usos son esenciales para su viabilidad. Las áreas centrales urbanas tradicionales son buenos ejemplos de esta posibilidad. Sin embargo, pocas ciudades utilizan coherentemente la diversidad de estos aspectos espaciales y estructurales existentes en su interior, según su potencial real.

La propia conformación difusa pero nuclearizada de las ciudades podría favorecer también el uso de sistemas colectivos en la circulación urbana, con nucleaciones alrededor de puntos o líneas de sistemas de transporte colectivo, minimizando los radios de desplazamiento peatonal entre los habitantes/usuarios y la estación. Sin embargo, las soluciones espaciales dispersas o más fragmentadas, sin nucleaciones definidas, inducen a una difusión mucho mayor de su circulación, incentivando, o incluso, casi obligando al uso del automóvil. La priorización de la utilización del automóvil, aquí considerado como un sistema de transporte individual ${ }^{4}$, ya que a pesar de su capacidad media para transportar 4 pasajeros, en ningún lugar del mundo, el promedio de pasajeros efectivos por viaje alcanzó dicho índice -2-, viene a constituir un equívoco en el funcionamiento intraurbano, por la naturaleza individual y no colectiva de la solución, como lo exigiría un sistema urbano intrínsecamente colectivo.

También en las estructuras urbanas más extendidas, su estructuración nuclearizada en torno a ejes regionales de transporte facilita más las soluciones colectivas, que la estructura completamente difusa (figura 4).

En vista de ello, el transporte por carretera se ha convertido en un devorador del espacio urbano y de energía de fuentes fósiles. De hecho, cuanto más la ciudad se dispersa, más se alargan las distancias y se hacen impracticables los transportes no motorizados, las densidades se enrarecen aún más y se inviabilizan los sistemas colectivos de transporte. De esta forma, a medida que la propagación de vehículos individuales aumenta, rápidamente saturan los corredores viales por su elevada voracidad para consumir las áreas destinadas a la circulación, llevando el sistema a congestionarse y a un bajo nivel de eficiencia.

La persistencia en resolver este aspecto mediante el automóvil, agrava el problema en la práctica, ya que la apertura de nuevas vías y la ampliación de las existentes acaban

$4 \quad$ El automóvil es considerado un transporte individual, a pesar de tener, en general capacidad para 4 o 5 personas, ya que en ningún país el promedio de pasajeros por automóviles en circulación alcanzó el índice de 2 pasajeros / vehículo. Los índices medios situados en el intervalo de I,4 y I,7 pasajeros por vehículo son los índices más comunes. 
Figura 3. Esquema urbano nucleado. Laboratorio del Ambiente Urbano y Edificado Laurbe, 2013 Fuente: Elaboración de los autores

Figura 4. Estructura nuclearizada en torno a los ejes de transporte. Laboratorio del Ambiente Urbano y Edificado (Laurbe/UFPB, 2013)

Fuente: Elaboración de los autores
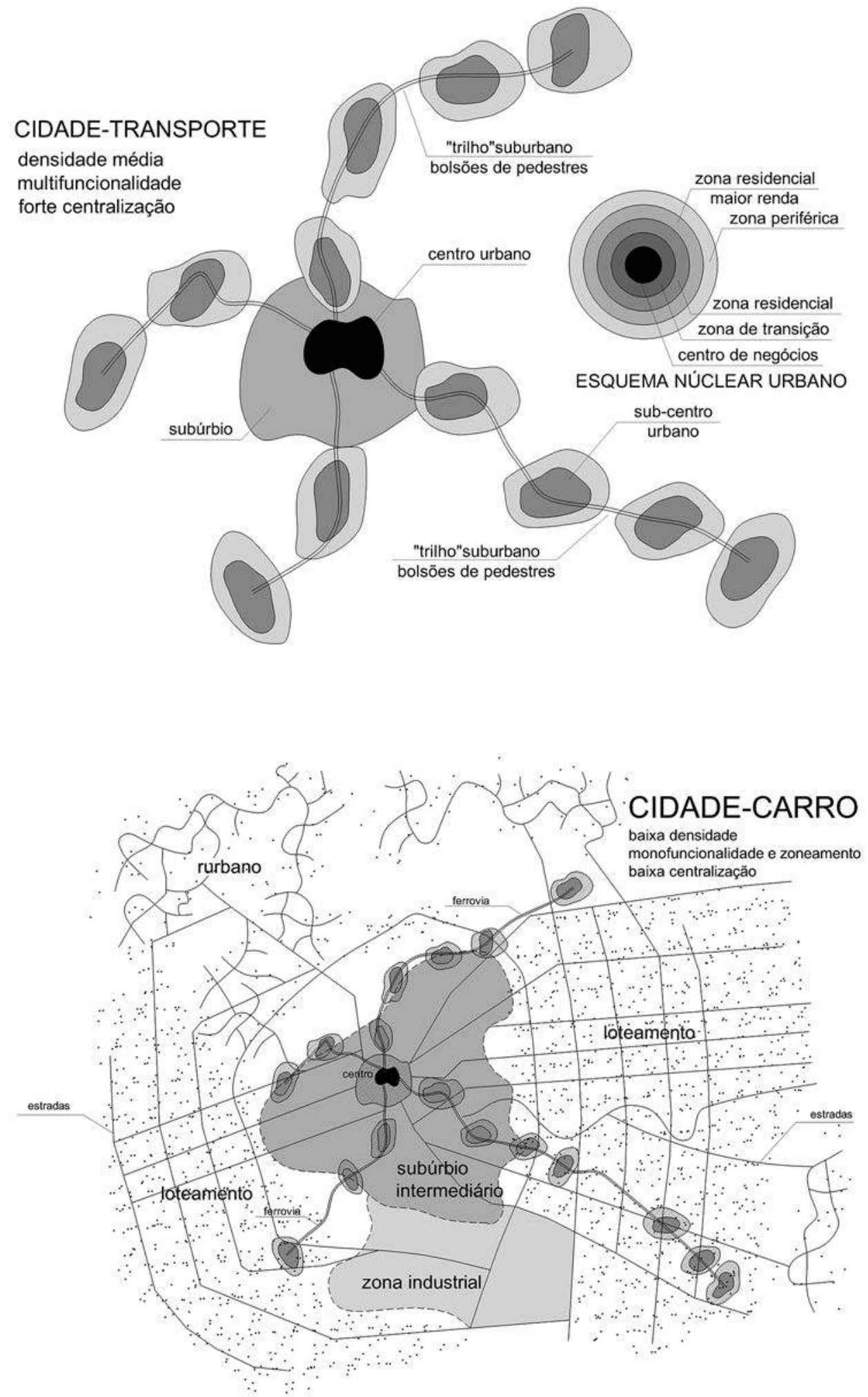
estimulando el uso del automóvil, continuando el ciclo vicioso y al mismo tiempo direccionando la planificación urbana a nuevos espacios para los automóviles, sea para circular, como para estacionar. Lo que podría tener un efecto más positivo sería la reestructuración de la ciudad hacia una organización físico-territorial más densa. Sin embargo, la estructura actual, particularmente en ciudades norteamericanas y latinoamericanas, ya muy dispersa, reduce las posibilidades de hacer más eficientes los corredores y rutas de transporte, como elementos influyentes en la reestructuración de la urbe.

De hecho, según Bochet, Gay \& Pini (2003), existe una conexión bastante estrecha entre las formas urbanas, la densidad, la diversidad de usos y la movilidad. Numerosos estudios, además de los autores citados, también demuestran que los volúmenes de flujos, las distancias y los medios de desplazamientos no solo están influenciados, sino determinados por la morfología urbana. Una ciudad más densa puede favorecer la diversidad y los desplazamientos de corta distancia, así como la utilización de transportes públicos colectivos. Por otro lado, ciudades difusas o dispersas, con distancias internas más largas y sectorización especializada, conduce siempre a la fuerte dependencia del automóvil.

Dentro de una visión histórica, también se puede indagar si la expansión urbana no sería exactamente una negación del carácter colectivo de la ciudad o si la naturaleza colectiva de la "polis" o de la "civitas" no estaría en camino de su destrucción. En una visión sociológica, a través del abordaje de la urbanidad, muchos autores, como Levy (1999) conjeturan que el debilitamiento de las centrales urbanas es el preludio de una victoria del individualismo contra el aspecto comunitario y social de las ciudades. Esta cuestión, en cierta forma, encuentra puntos comunes en relación con la tesis planteada por Claval (2000), que demuestra que es precisamente en el centro urbano donde cada ciudadano se funde en un gran ser colectivo, que es la comunidad urbana.

De hecho, incluso en su sentido físico, los espacios centrales tienen un efecto propio de doble convergencia: la convergencia física que lleva al encuentro social y a la integración físico-espacial y la convergencia cultural y simbólica, en la cual las personas, ya sea individualmente $o$ en comunidades urbanas, se identifican y se reinventan cada día.

\section{EL SISTEMA URBANO COMPACTO Y SUS INFLUENCIAS SOBRE LA SOSTENIBILIDAD Y LA CALIDAD DE VIDA}

La búsqueda de la ciudad como espacio adecuado para la vida humana ha sido constante y demostrada por la tendencia histórica en la evolución de la tasa de urbanización, en diversos períodos y en diversos grados de dificultad de la vida urbana. Aún en períodos de grandes problemas sociales, de epidemias, de conflictos, de desigualdades, la sociedad humana parece reinventar su esperanza en la ciudad. De hecho, la idea de que "el aire de la ciudad libera" parece conservarse a lo largo del tiempo y la hace siempre atractiva, aunque, en el actual contexto urbano se trate de dispersar su estructura, manteniendo las estructuras urbanas y rurales a distancias interpersonales, en niveles contradictorios. Si en 1950 la población urbana mundial era del $29 \%$, con un total de 2.500 millones de personas, actualmente ya superó el $50 \%$ de la población total estimada en más de 7 mil millones. Con base en la última cifra, las estimaciones de población urbana del 2050 alcanzarán casi 10 mil millones de individuos (un $70 \%$ del total). Es decir, la población actual del mundo será, en menos de cuatro décadas, la población urbana mundial. Sin embargo, el modelo urbano disperso actual ya presenta sus límites y problemas (figuras 5 y 6 ). 
Figura 5. Relación entre transporte y consumo de energía (Gigajoules per cápita al año) en conformidad con la densidad urbana (habitantes por ha)

Fuente: Silva (2011) apud Newman \& Kenworthy, 1989; Atlas Environnement du Le Monde Diplomatique, 2007
Figura 6. Gráfico del estudio de Newman y Kenworthy en 1989. Este se refiere a la demostración de una relación entre la densidad urbana global ( $\mathrm{m}^{2}$ / persona) y el uso de energía de transporte (gigajoule/persona)

Fuente: Silva (20II) apud Newman \& Kenworthy, 1989
Transport-related energy consumption Gigajoules per capita per year

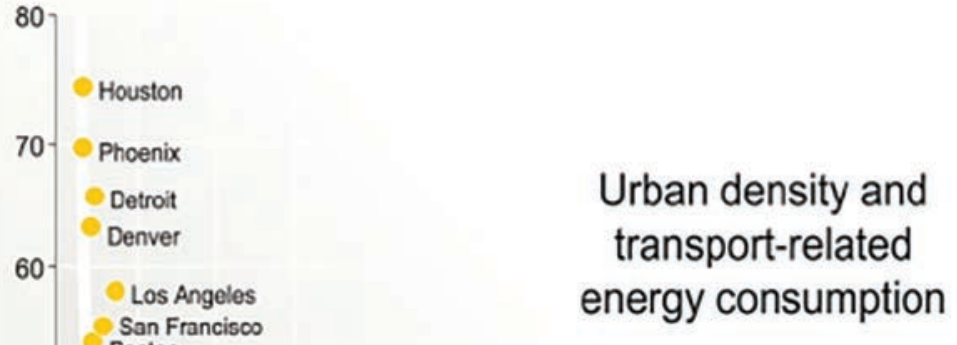

50- Washington Source: Nowman et Kenworthy, 1989;

50. Chicago

New York

40

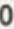

- Perth Toronto

30

- Brisbane

- Melbourne

Sydney

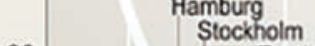

20

Stockholm

- Frankfurt

Paris Brussels

London $=2$ Munich

10-Copenhagen West Berlin

Amsterdam

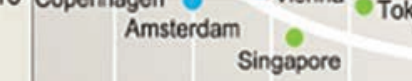

0

Singapore - Moscow

North American cities

- Australian cities

- European cities

- Asian cities

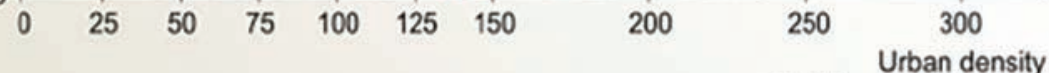

Inhabitants per hectare

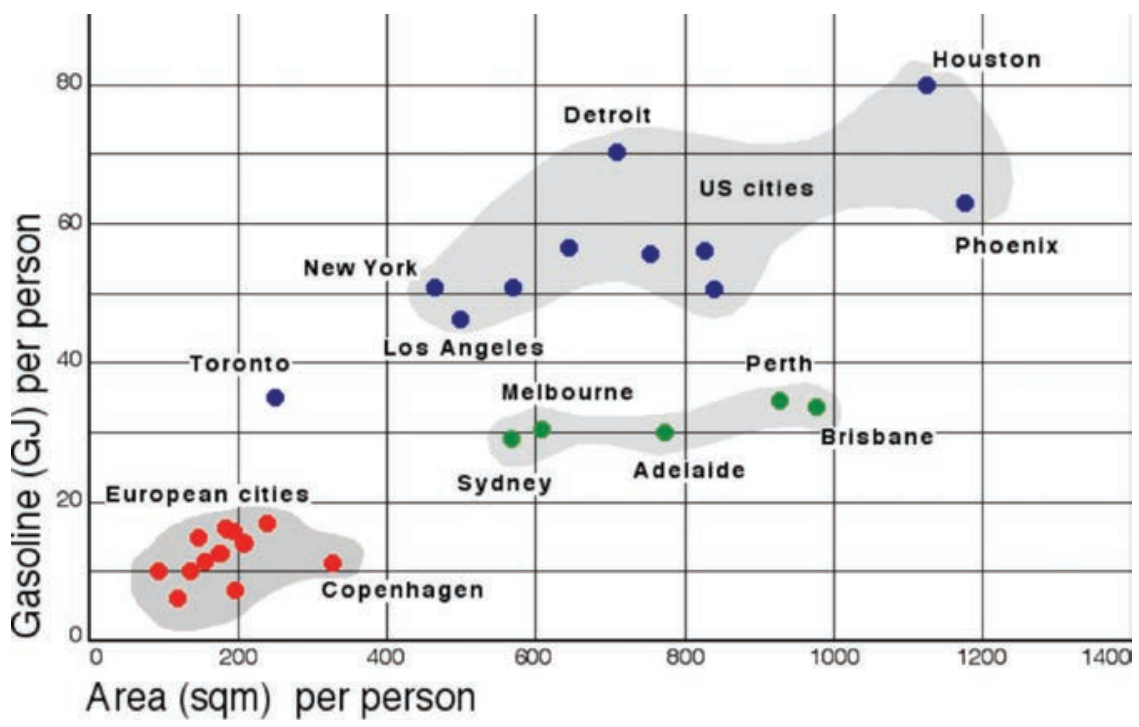

5 Disponible en: <http://maps.grida.no/go/graphic/urban-density-and-transport-related-energy-consumption>. Acceso en: I I/08/201 I. 
Probablemente, la cultura contemporánea, de carácter mucho más individualista que comunitario o solidario, sea uno de los motivos de ese "distanciamiento" intraurbano. Otro motivo bien claro sería la adecuación del diseño urbano a la escala de velocidad del automóvil, con las distancias debidamente adaptadas. Este factor asociado al contenido especulativo y de invención de lo "nuevo", presentes en el mercado inmobiliario, hace que la ciudad acabe ocupando áreas mucho más grandes de lo que realmente se necesita.

No obstante, se pueden comprender aspectos espaciales de dispersión urbana de forma más clara por medio de ejemplos más cercanos, tomando como base la ciudad de João Pessoa, capital del estado de Paraíba, ubicada al nordeste de Brasil, con una población de 723.5I 5 habitantes (Censo IBGE, 2010) y una densidad poblacional de 62,95 hab/ha, ocupando un área de I I.493, I 4 ha. Si se hubiese adoptado la recomendación del PNUD/ SUDENE, para el nordeste brasileño, de $250 \mathrm{hab} / \mathrm{ha}$, el área ocupada se reduciría a 2.699,05 ha. Además, si se hubiese adoptado la densidad considerada como óptima, desde el punto de vista del aprovechamiento infraestructural y de los ingresos urbanos (400 hab/ha), el área ocupada llegaría a apenas I.686,9I ha. En otras cifras, el área necesaria sería solo del 14,69\% del área actualmente ocupada.

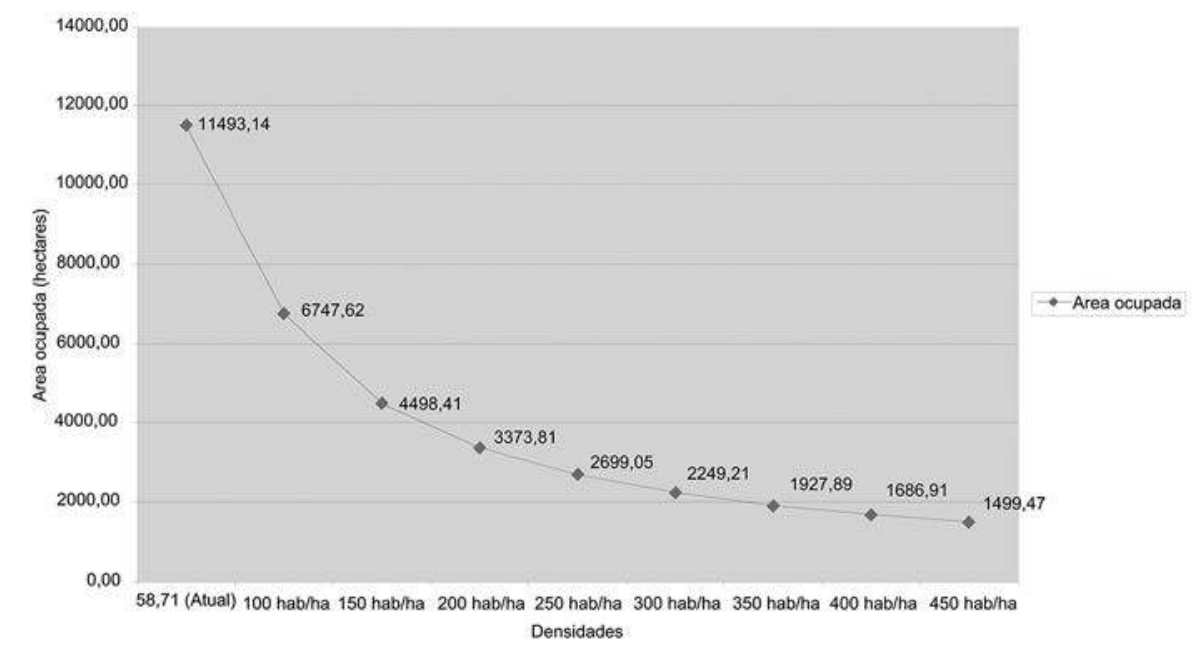

Sin embargo, la densidad, por sí sola, no informa totalmente sobre la eficiencia interna de aprovechamiento de los espacios y de articulación e integración entre los diversos usos. Una densidad en altura pero con grandes distancias entre sus elementos internos, generaría también una estructura relativamente densa, pero de gran discontinuidad interna. La condición más favorable es que, además de la densidad y de las adecuaciones morfológicas, también se haga presente una articulación interna más favorable a las interfaces funcionales intraurbanas. Así, la economía espacial y ambiental también estaría acompañada por una fuerte aproximación entre los usos, la mejora de las accesibilidades y, por lo tanto, de las oportunidades para cada ciudadano.

Además de la economía del área natural o rural ocupada precozmente por la urbanización periférica, la densificación con menor cantidad de vacíos y áreas de preservación internas a la estructura urbana, haría más viable su conservación por medio de usos compatibles y socialmente útiles, como parques y bosques urbanos. Incluso las áreas verdes internas merecen mejor gestión y dimensionamientos acorde a la escala humana y ambiental y no la escala del automóvil, como se ha adoptado en muchos casos.
Figura 7. Simulación del área física ocupada por la población de la ciudad de João Pessoa-PB con relación a diferentes densidades urbanas supuestamente adoptadas

Fuente: Adaptación de los autores a partir de Ribeiro \& Oashi (2010) 
Las grandes cantidades de áreas verdes preservadas y posteriormente destinadas a una función socio-ambiental, en una ciudad dispersa, dificultan la viabilidad de su adecuado tratamiento y las expone a la presión demográfica, a la agresión, a los "conflictos de borde" y a la ocupación inadecuada 6 . Estos fenómenos sobresalen particularmente en las regiones más pobres, donde existen menores recursos financieros para la implantación de equipamientos e infraestructuras. Por otro lado, las áreas públicas tienden a convertirse paulatinamente en áreas privadas conforme a las actuaciones y a las fuerzas del mercado especulativo inmobiliario sobre la ciudad.

En la construcción material de la ciudad y de sus dispositivos técnico-espaciales, la densificación permitiría también una economía considerable en la infraestructura, en la red de drenaje urbano y, principalmente, en lo que se refiere al sistema de circulación y transporte intraurbano. Esta economía material en la construcción y funcionamiento de la ciudad ya ha sido considerada por muchos autores, como Richard Rogers (2005), en Cities for a small planet, Salvador Rueda (1999), Brian Edwards (2005) y Mascaró (2004), entre otros.

La reducción espacial y la densificación poblacional, además de minimizar las distancias (viabilizando desplazamientos no motorizados y reduciendo el consumo en los desplazamientos motorizados), reducirían también el consumo material para la construcción de la ciudad y haría mejor su funcionamiento. Su funcionamiento consumiría menos tiempo, menos espacios, menos energía y, por lo tanto, tendría un nivel más bajo de emisión de contaminantes vehiculares. La concentración y densidad de la población haría más viable la utilización de sistemas de transporte con mayor capacidad y eficiencia, así como fuentes energéticas no emisoras, como los $\mathrm{VLT}^{7}$ (vehículo ligero sobre rieles o light rail) eléctricos y otros.

En este sentido, las ciudades compactas, contrario a lo que promueven algunos autores que las catalogan como ciudades sofocantes, contaminadas y ruidosas, pueden tener características completamente opuestas, gracias a la reducción del uso del automóvil, principal fuente de contaminantes atmosféricos y de ruido urbano. Si trabajos como el de Maignant (2005), por ejemplo, no llegan a resultados en favor de las ciudades compactas, afirmando que las mismas presentan mayor concentración de contaminantes, en virtud de su mayor fragmentación, tal hecho se deriva de una hipótesis equivocada, donde el nivel de emisión, supuestamente, sería igual para los dos casos. Sin embargo, en las ciudades compactas, la reducción de la emisión de la fuente, lograda gracias a la proximidad entre las funciones y las nuevas posibilidades de desplazamiento, en sustitución al automóvil, sería su mayor contribución. La partición atribuida a la densificación no acumularía contaminantes a no ser que estos fuesen emitidos desde su interior.

Por otro lado, los impactos pueden ser minimizados o potenciados conforme al grado de planificación urbana e inversiones en modalidades más eficientes y menos contaminantes, asertiva válida tanto para la ciudad compacta, como para la ciudad dispersa, aunque sea esta, en promedio, la que más contamina y emite gases invernadero/per cápita. (figura 8). En otras palabras, al contrario de lo que generalmente se imagina, las ciudades más compactas pueden ser menos contaminadas, ya que minimizan el efecto generador principal (mayor uso de vehículos particulares).

6 En un ambiente urbano, la preservación y conservación de la naturaleza, se hace más eficientemente, no por medio de la intocabilidad o de la conservación pura y simple, sino como consecuencia de la atribución de una función social más adecuada a su característica como área que debe ser preservada. Esta percepción de la asociación entre la necesidad de la preservación y la utilización colectiva del espacio lleva al ciudadano a estar en una posición mucho más amistosa y solidaria en relación con el espacio verde.

7 VLT en portugués significa "Vehículo liviano sobre rieles", o en inglés: "light rail transit" (Irt), "fast tram" o "tram". 


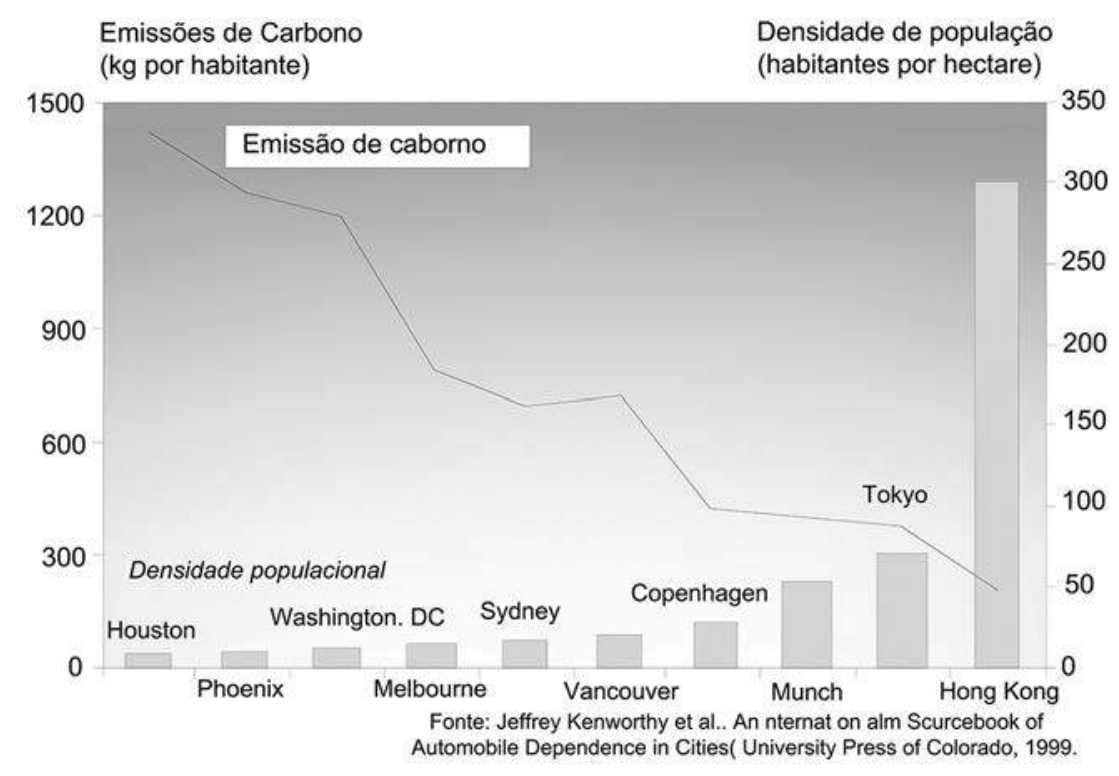

Además, las condiciones de dispersión no están tan directamente ligadas a la densidad de ocupación. Existen otros factores, de carácter cualitativo, como la porosidad estructural que, aun en condiciones de ocupaciones muy densas, podría permitir mejores condiciones de dispersión local y minimizar su concentración interna en los ambientes urbanos. Para una misma densidad, serían posibles varios grados de porosidad o permeabilidad de sus estructuras edificadas y entre las mismas. Una mejor porosidad permitiría una buena renovación de aire, aún en ambientes de alta densidad construida. Este principio también fue adoptado en el urbanismo modernista, aunque en este las distancias entre los volúmenes edificados fueron dimensionadas según la previsión de los grandes flujos vehiculares. Este principio compacto se basa en el equilibrio de la circulación con sistemas no motorizados o sistemas motorizados de transporte colectivo (de alto rendimiento y menor emisión per cápita) y, por lo tanto, sus dimensiones podrían ser menores, más eficientes e higienizadas.

\section{LA COMPACIDAD URBANA Y LA CALIDAD DE VIDA}

Además de los aspectos ambientales citados, una discusión frecuente, entre algunos autores sobre la ciudad compacta, es que la misma ofrecería un menor índice de calidad de vida por la sobrecarga de los equipos y servicios urbanos, la reducida cantidad de áreas verdes y de espacios intraurbanos y la mínima presencia de naturaleza en los espacios internos de la ciudad. En realidad, ese pensamiento forma parte de una serie de mitos urbanos.

Las densidades más elevadas, si se adoptan con una morfología conveniente, lejos de sobrecargar los servicios públicos y los equipamientos urbanos, permiten optimizar cualitativamente su uso, por el mejor aprovechamiento social del espacio y por la mejor accesibilidad. Por ejemplo, la provisión de escuelas para sectores urbanos de baja densidad se puede dar por medio de un número mayor de pequeñas escuelas, dispersas sobre el territorio y funcionando continuamente con recursos mínimos, o en su defecto por equipamientos de mayor capacidad, localizados de forma más dispersa y con más dificultades de acceso por las distancias.
Figura 8. Densidad de la población - Emisión de carbono de los transportes en 1990

Fuente: Adaptación de los autores a partir de Kenworthy, J. et al. (1999) 
Figura 9. Número de equipamientos - número de personas atendidas por equipamientos ante diversas densidades, para una población de 500.000 habitantes, considerando la posibilidad de 4 opciones de elección en un radio de $500 \mathrm{~m}$ Fuente: Adaptación de los autores a partir de Ribeiro \& Cop (2010)
En la modalidad compacta, se podrían tener equipamientos más completos (proyectados para un mayor número de usuarios), con mayores recursos internos (bibliotecas bien formadas, laboratorios, equipos de informática e investigación, equipos deportivos y de práctica profesional, etc.) y con un índice de proximidad que permitiría, incluso, mayor número de opciones para cada familia usuaria. En la práctica, habría menos equipamientos aunque serían más completos y estarían más cercanos a las viviendas (mejoría cualitativa), habiendo mayor superposición de áreas de influencia y mejorando el número de opciones de elección (mejora cualitativa). Es muy cierto que, en condiciones de densidades más altas, se vuelve más difícil encontrar lotes de gran tamaño, capaces de acoger dichos equipamientos o, inclusive, su adquisición podría ser más costosa. Sin embargo, tales costos podrían ser compensados con la reducción del número de los equipamientos necesarios y por la aplicación de herramientas legales y tributarias compensadoras del gasto público, frente a la valorización de las áreas consolidadas ${ }^{8}$.

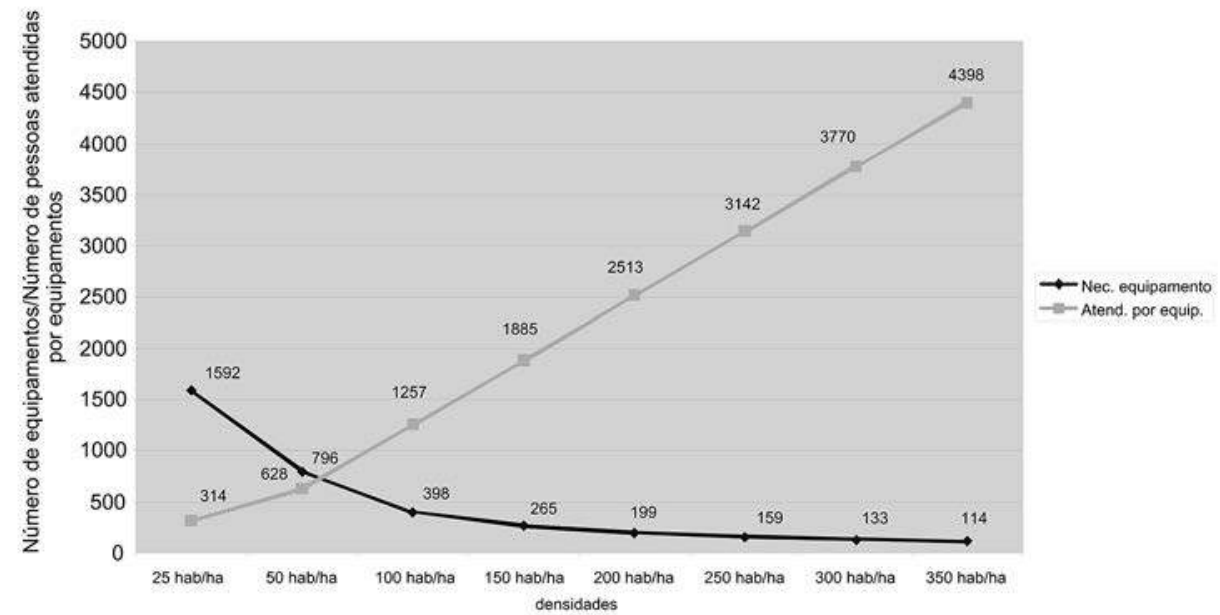

Es evidente que en equipamientos que exijan límites de escala o que el número de usuarios sea limitado proyectualmente, como en el caso de escuelas infantiles y de enseñanza básica, donde los equipamientos deberían tener una escala más compatible con la reducida edad de los usuarios, la adopción de este principio (pocos equipamientos, pero más grandes) podría no ser la más indicada. Este hecho sería problemático en presencia de altos niveles de densificación. Sin embargo, sería mucho más viable en segmentos de densidades medias (alrededor de 200 hab/ha). En una ciudad densa, las familias con hijos pequeños normalmente buscan áreas con menores densidades. En algunas ciudades más densas existen escuelas infantiles bien distribuidas, ocupando áreas anexas a usos residenciales, y acompañadas por pequeños jardines cercanos a los equipamientos destinados al esparcimiento infantil. Esta conclusión también es afirmada por Haughley (2005), que resalta además que, en densidades mayores, las familias, por lo general, son de dimensiones más reducidas y en proporción demandan menos equipamientos escolares, reduciendo, por lo tanto, la saturación de los equipamientos ubicados en las áreas centrales.

8 Esta adquisición o puesta a disposición de terrenos también se facilitaría con la redistribución de áreas, facilitada por la compactación urbana. Los proyectos de urbanización y nuevas parcelaciones (loteos) deberían conceder más áreas para equipamientos públicos y menos áreas para sistema vial, ya que, en condiciones de mayor compacidad, la demanda cuantitativa de vías sería mucho menor y la utilización de sistemas más eficientes, con menor consumo de espacio, sería aún mayor. 
Pero, seguramente, el aspecto más criticado por los opositores de la ciudad compacta sería el de la supuesta falta de espacios verdes y áreas libres y del mínimo contacto que el habitante de una ciudad compacta tendría con la naturaleza. En las hipótesis formuladas por los partidarios de ese raciocinio prima el hecho de que los habitantes de dicha ciudad, al tener menor contacto con la naturaleza en el espacio interurbano, irían inexorablemente a buscar residencias secundarias en áreas naturales, agravando el problema de la dispersión.

Podríamos, sin embargo, examinar esta crítica en algunos aspectos, fundamentalmente, como los siguientes: i. Distancia media de cada habitante en relación con la naturaleza extraurbana; ii. Posibilidades y potencialidades de uso y contacto con áreas verdes intraurbanas y, iii. Posibilidades técnicas de arborización de vías urbanas.

\section{i. Distancia media de cada habitante en relación con la naturaleza extraurbana}

En una ciudad más dispersa aunque se pueda encontrar, en sus áreas intersticiales, una gran cantidad de cobertura vegetal, estas son, en realidad, vacíos urbanos; las áreas sujetas a repentinos cambios de uso a lo largo del tiempo. La naturaleza aún no ocupada por el uso urbano se vuelve más distante. En una simulación para una ciudad isotrópica teórica de 400.000 habitantes, la distancia media entre los habitantes y el área natural extraurbana, aumentaría considerablemente si las densidades fuesen menores. Por ejemplo: para un aumento de la densidad adoptada, de 50 hab/ha a 100 hab/ha, la ciudad reduciría su radio y su área, y la distancia media de los ciudadanos hacia el área natural externa se reduciría de $5,05 \mathrm{~km}$ a $3,57 \mathrm{~km}$.

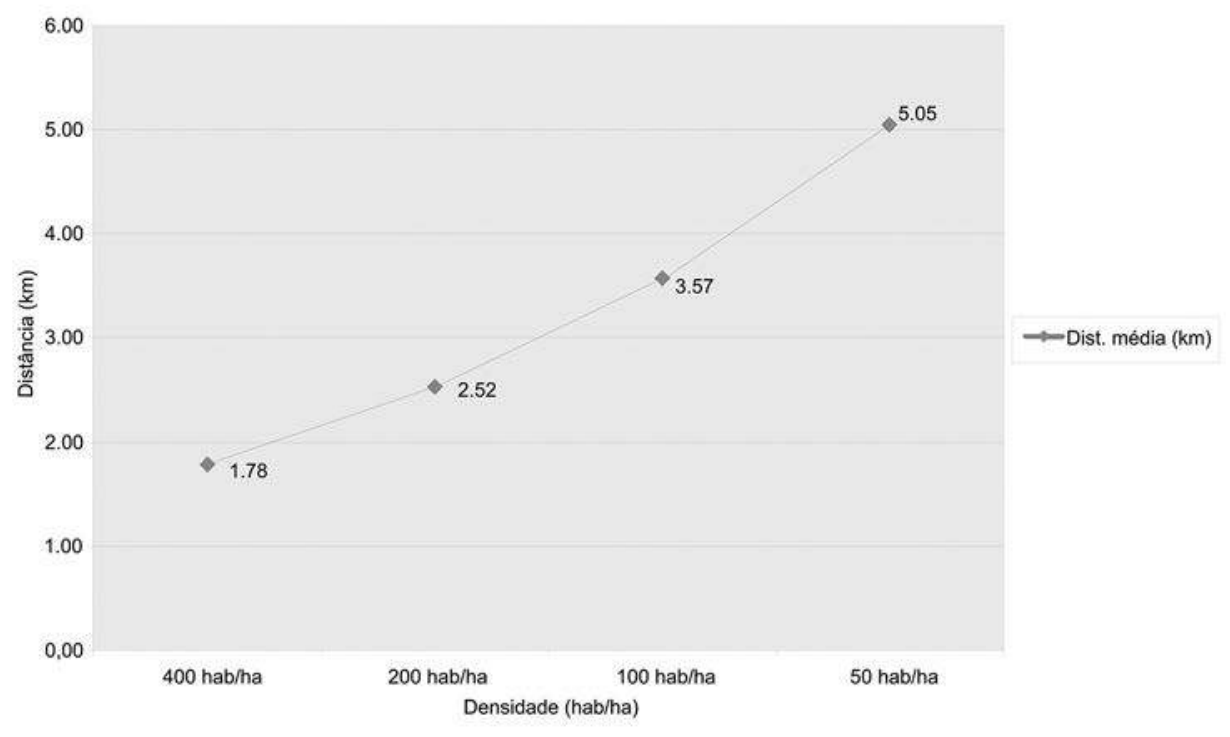

\section{ii. Posibilidades de uso y contacto con áreas verdes intraurbanas}

Si se proyectan más parques pero de menores dimensiones (mucho más adecuados a la estructura de una ciudad compacta), en sustitución de la minoría de parques de grandes extensiones, se podría obtener una mayor extensión del borde urbano, concomitantemente con una mejor distribución espacial en la ciudad, lo que proporcionaría una mejora
Figura 10. Distancia promedio (en $\mathrm{km}$ ) desde las áreas naturales periurbanas, para habitantes de una ciudad isotrópica teórica de $400 \mathrm{mil}$ habitantes, en diferentes condiciones de densidad bruta poblacional

Fuente: Adaptación de los autores a partir de Ribeiro \& Cop (2010) 
Figura II. Simulación de diferentes extensiones relativas $\left(\mathrm{ml} / \mathrm{km}^{2}\right)$ de bordes de parques urbanos, por clase de tamaño y por fraccionamiento del área total destinada a los parques urbanos

Fuente: Adaptación de los autores a partir de Ribeiro \& Cop (2010) significativa del contacto del habitante urbano con el paisaje natural y con las posibilidades de disfrutar de las áreas verdes. En esta contribución, estarían también algunos efectos microclimáticos que son particularmente mejor sentidos en los límites de los parques ${ }^{9}$, como se demuestra en la figura I I en la simulación sobre la extensión de las áreas de los parques, con diferentes clases de dimensiones y diferentes fraccionamientos. De la misma manera, las áreas verdes intraurbanas de gran porte, aunque son consideradas beneficiosas por su contribución paraclimática y como oferta de área para el ocio, si fuesen fraccionadas en varios parques menores, tendrían una utilización más óptima. Esto aumentaría la superficie utilizable, principalmente en la frecuencia diaria. Varios autores han ya constatado que las áreas de los grandes parques se utilizan en una proporción muy baja, particularmente en días hábiles, mientras que los parques pequeños muestran un mayor porcentaje de utilización del espacio.

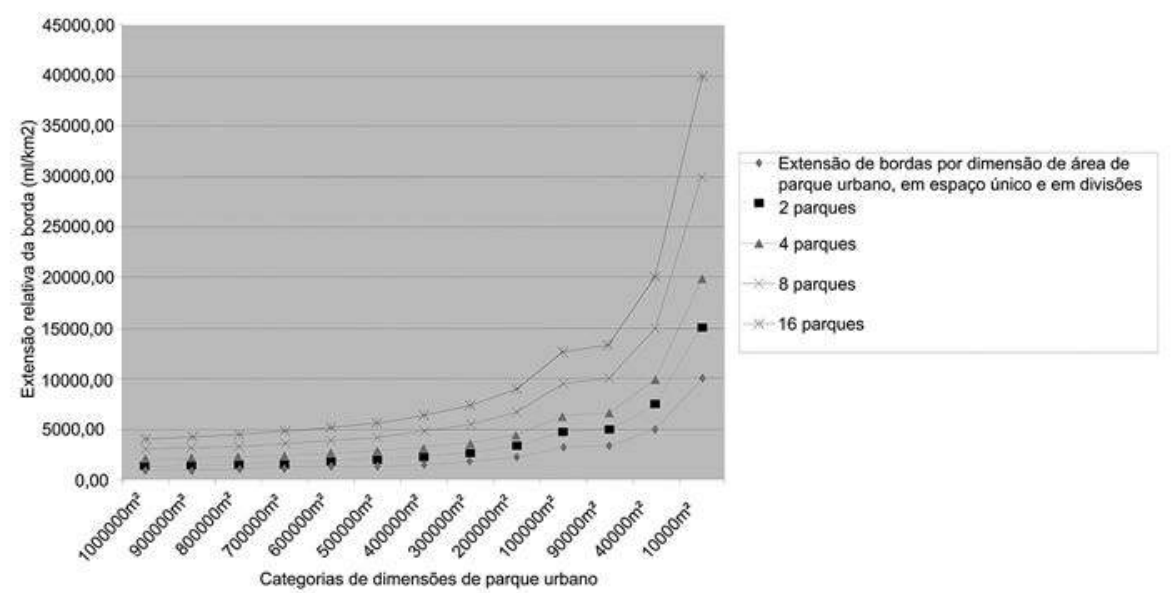

Por lo tanto, además de una ganancia en la eficiencia de la utilización del espacio, se tendría, en esos casos, una ganancia en el carácter público del espacio, en el sentido de que serían espacios donde, por su escala, los ciudadanos no solo se encontrarían con la naturaleza sino que también se encontrarían entre sí para fomentar su convivencia social. Gorra-Gobin ( 1998 y 200 I) destaca la importancia de dos aspectos ambientales y sociales de las áreas verdes, mostrando sus elementos vegetales (de importancia ambiental) y sus elementos minerales, que, junto a los gramados, sirven como piso o base física para los intercambios sociales.

En la figura 12 se puede observar que, en el caso de parques cerrados con una única abertura de alguno de sus lados, parques pequeños (en el rango de $10.000 \mathrm{~m} 2$ ) son aquellos en los cuales su espacio es plenamente utilizado todos los días. En el caso de parques con área de $1.000 .000 \mathrm{~m} 2$, el porcentaje de área utilizada (en días hábiles) se reduce aproximadamente al $2 \%$. Por lo tanto, para la concepción de una ciudad compacta también sería necesaria una nueva readaptación de la escala humana. Así bien, la ciudad compacta puede constituirse como una re-humanización del espacio urbano.

9 Los "efectos de borde" en la visión de los urbanistas ecologistas y teniendo como referencia los bosques naturales, serían más negativos que positivos, pues se refieren al impacto del ambiente urbano sobre el bosque natural, con foco en este último. Sin embargo, en las áreas verdes urbanas, donde el foco de atención es el medio antrópico y no propiamente los ecosistemas, los efectos se podrían considerar siempre positivos, tales como los efectos microclimáticos, paisajísticos, entretenimiento, accesibilidad al ocio, etc. 


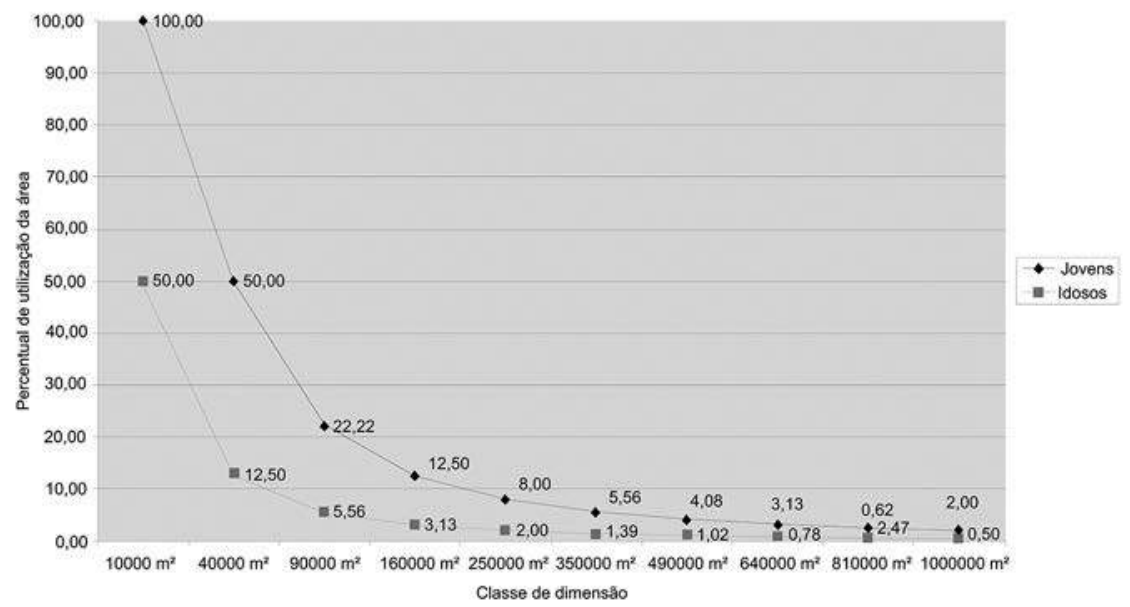

\section{iii. Posibilidades técnicas de arborización de vías urbanas}

Si bien, sobre el aspecto de las áreas verdes, se presupone una mejor optimización de su utilización social en el caso de la compactación, en términos de la arborización del sistema vial observa que la necesidad de un sobredimensionamiento y multiplicación de las franjas viales de circulación vehicular se presenta con mayor frecuencia en condiciones de dispersión urbana o fusión de la estructura urbana con la estructura regional.

En una situación de compacidad urbana se propiciarían sistemas más eficientes de circulación, permitiendo la liberación de franjas para una arborización urbana continua. Como señala Juhnke (1968), la capacidad de circulación en cada banda de 3 metros de ancho de vía, en horas pico de circulación en áreas centrales urbanas no favorece el automóvil, pero sí los sistemas individuales no motorizados (peatones y ciclismo) y los sistemas colectivos de transporte, como se puede observar en la tabla 2. Por lo tanto, el ahorro de franjas viales a partir de la compactación y de cuan óptimo sea el empleo de transportes motorizados colectivos y de circulación no motorizada individuales, permitiría la utilización de las áreas asignadas inicialmente a la circulación vehicular a la arborización, aumentándose de esa forma el contacto del ciudadano con el ambiente placentero, verde y sombreado que proporcionan los árboles. En este caso, sin embargo, sería necesario ajustar los perfiles viales (compartimento resultante entre los edificios circundantes y el canal viario), de modo que la relación visual (altura/ancho) no supere determinados límites que perjudiquen o dificulten el crecimiento de la vegetación arbórea (ya sea por sombra o por estrechez del canal).

De esta forma, la demanda adicional de circulación, con la compactación urbana, podría ser bien atendida con la sustitución de las franjas para automóviles por vías peatonalizadas, 4,5 veces más eficientes en pequeñas distancias, o por corredores preferenciales para el autobús o, preferentemente, el VLT (vehículo ligero sobre rieles, light rail o tram), siendo este 16,5 veces más eficiente. Las bandas sobrantes se podrían transformar en franjas verdes. En el caso del VLT, la propia banda utilizada puede ser de césped, conformando un espacio vial que podría ser un verdadero parque lineal.
Figura 12. Porcentaje promedio de utilización diaria del espacio interno de parques urbanos cerrados, con una única abertura, para diferentes condiciones de dimensionamiento

Fuente: Adaptación de los autores a partir de Ribeiro \& Cop (2010) 
Tabla 2. Capacidad y potencia de circulación de una banda vial de 3 metros de ancho para diferentes modos de desplazamientos, en áreas urbanas y hora de pico

\begin{tabular}{lcccc}
\hline $\begin{array}{c}\text { Modos de } \\
\text { transporte }\end{array}$ & $\begin{array}{c}\text { Capacidad máxima } \\
\text { por hora } \\
\text { (pasajeros / hora) }\end{array}$ & $\begin{array}{c}\text { Velocidad comer- } \\
\text { cial media } \\
\text { (km / hora) }\end{array}$ & $\begin{array}{c}\text { Potencia máxima } \\
\text { de circulación } \\
\text { (pass. km/hora) }\end{array}$ & $\begin{array}{c}\text { Relación de las } \\
\text { capacidades } \\
\text { comparadas con el } \\
\text { automóvil }\end{array}$ \\
\hline Peatonal & 16.000 & 4 & 64.000 & 4,5 \\
\hline Bicicletas & 5.400 & 12 & 65.000 & 4,5 \\
\hline Coche & 1.200 & 12 & 14.400 & 1 \\
\hline Autobús (55 lug) & 5.600 & 10 & 56.000 & 6 \\
\hline Autobús (83 lug) & 8.300 & 10 & 83.000 & 16,5 \\
\hline VLT (simples) & 24.000 & 10 & 240.000 & 42,0 \\
\hline VLT (doble/autom) & 40.000 & 15 & 600.000 & \\
\hline
\end{tabular}

Fuente: Adaptado a partir de Juhnke (1968).

\section{LA COMPACIDAD URBANA Y LA JUSTICIA SOCIAL}

Además de los efectos ecológico-económicos, así como los efectos sobre la calidad de vida urbana aquí presentados, se podría también sugerir posibles beneficios en términos de justicia social, ya que la ciudad compacta equilibraría aún más las condiciones de accesibilidad y oportunidades urbanas y reduciría (al menos espacialmente) la segregación social, contribuyendo a una mejor equidad. Este aspecto completaría los elementos básicos de la sostenibilidad (ambientalmente adecuado, económicamente viable y socialmente justo).

La mejor distribución de las áreas verdes en la estructura urbana también contribuye a una mejor organización espacial o a un impacto positivo sobre el valor de la tierra urbana. En ese sentido, la misma especulación inmobiliaria, que normalmente ocurre en las áreas urbanas vecinas a parques y áreas verdes, se disminuiría gracias a una mejor distribución espacial del "bien" público. En este sentido, una ciudad compacta se caracterizaría por ser una ciudad de inversiones y de oportunidades más equitativas; una ciudad con menos especulación y mejor justicia social. El afán de los especuladores por privilegios y grandes ganancias, en detrimento de la colectividad, se vería minimizado ante una condición de compacidad urbana, gracias a la producción de una nueva escala, así como a una oportuna organización espacial y funcional.

De hecho, el enfoque inspirador de Harvey (1980) sobre las relaciones existentes entre la justicia social y el contexto urbano, han posiblemente influenciado autores como Burton (200 I) y otros más, a conducir un análisis sobre el tema y a intentar definir las influencias de la compacidad urbana sobre la justicia social. En este abordaje, varios aspectos también se superponen a aquellos considerados en la evaluación de la calidad de vida urbana. A partir de un cuadro realizado por Burton (200I), donde se establecen una serie de factores positivos y negativos y las influencias que la compacidad urbana tendría sobre los mismos, se presenta aquí un nuevo marco perfeccionado, basado en un análisis nuevo y propio que tienen además en cuenta la posición de otros autores, como se puede observar en la tabla 3.

Aunque es un tanto prematuro concluir que las estructuras urbanas compactas contribuyan efectivamente a la justicia social, se podría sugerir que el mejoramiento de la accesibilidad general, de forma más isonómica, sin privilegiar a propietarios y a usuarios del automóvil; la aproximación física no solo entre los diferentes usos, sino también entre ricos y pobres, la reducción de la segregación socio-espacial y, aún más, el mejoramiento 
de la eficiencia de los espacios públicos, como lugar de encuentro social y de convivencia, permitirían múltiples ganancias para el escenario social de la vida urbana, con sensibles beneficios en pro de la aproximación, cohesión y co-participación en el medio urbano.

Tabla 3. Factores positivos y negativos de la ciudad compacta para la justicia social

\begin{tabular}{|c|c|c|c|c|}
\hline Factores considerados & $\begin{array}{l}\text { Evaluación de la } \\
\text { influencia }\end{array}$ & $\begin{array}{l}\text { Consensual / } \\
\text { polémica }\end{array}$ & Autores considerados & $\begin{array}{c}\text { Contribución propia al } \\
\text { análisis }\end{array}$ \\
\hline $\begin{array}{l}\text { Mejores accesos a las } \\
\text { oportunidades }\end{array}$ & Positiva & Consensual & $\begin{array}{c}\text { Burton (200I); } \\
\text { Rees (I988); Bromley } \\
\text { \& Thomas (1993) }\end{array}$ & $\begin{array}{l}\text { Es incuestionable, es } \\
\text { una de las contribucio- } \\
\text { nes más claras. }\end{array}$ \\
\hline $\begin{array}{l}\text { Mejores índices de } \\
\text { acceso a empleos }\end{array}$ & Incierta & $\begin{array}{l}\text { No consen- } \\
\text { sual }\end{array}$ & $\begin{array}{c}\text { Beer (1994); Laws } \\
\text { (1994); Ribeiro } \\
\text { (2008) }\end{array}$ & $\begin{array}{c}\text { La mejora de la accesi- } \\
\text { bilidad física al empleo } \\
\text { es incuestionable. Pero } \\
\text { hay otros factores } \\
\text { aún más dominantes, } \\
\text { como la política y la } \\
\text { globalización. }\end{array}$ \\
\hline $\begin{array}{l}\text { Difícil acceso a las } \\
\text { zonas verdes }\end{array}$ & $\begin{array}{l}\text { Injustamente } \\
\text { considerada } \\
\text { negativa por la } \\
\text { mayoría de los } \\
\text { autores }\end{array}$ & $\begin{array}{l}\text { No consen- } \\
\text { sual }\end{array}$ & $\begin{array}{l}\text { Breheny (1992); } \\
\text { Knight (1996); Ribei- } \\
\text { ro (2008) }\end{array}$ & $\begin{array}{c}\text { La compacidad urbana } \\
\text { no significa necesaria- } \\
\text { mente escasez de es- } \\
\text { pacios verdes. Aunque } \\
\text { bien dimensionados su } \\
\text { uso sería apenas más } \\
\text { eficiente. }\end{array}$ \\
\hline $\begin{array}{l}\text { Grandes oportunida- } \\
\text { des para bicicletas y } \\
\text { desplazamientos a pie }\end{array}$ & $\begin{array}{l}\text { Considerada } \\
\text { positiva, pero } \\
\text { ambigua }\end{array}$ & $\begin{array}{l}\text { No to- } \\
\text { talmente } \\
\text { consensual }\end{array}$ & $\begin{array}{l}\text { Bourne (1992); New- } \\
\quad \operatorname{mann}(1992)\end{array}$ & $\begin{array}{l}\text { La compacidad mejora } \\
\text { las relativas posibili- } \\
\text { dades por hacer las } \\
\text { distancias más practi- } \\
\text { cables, aunque algunos } \\
\text { autores consideran la } \\
\text { densificación como un } \\
\text { fuerte inhibidor del } \\
\text { uso de la bicicleta. }\end{array}$ \\
\hline $\begin{array}{l}\text { Mejora del transporte } \\
\text { colectivo }\end{array}$ & Positiva & $\begin{array}{l}\text { Totalmente } \\
\text { consensual }\end{array}$ & $\begin{array}{l}\text { ECOTEC (1993); } \\
\text { Goodschild (1994) }\end{array}$ & $\begin{array}{l}\text { Ningún autor expresa } \\
\text { dudas sobre este } \\
\text { positivo aporte. }\end{array}$ \\
\hline $\begin{array}{l}\text { Reducción de los } \\
\text { espacios de vida y con- } \\
\text { vivencia doméstica }\end{array}$ & Negativa & $\begin{array}{l}\text { No consen- } \\
\text { sual }\end{array}$ & $\begin{array}{l}\text { Forster (1994); } \\
\text { Stretton (1996) }\end{array}$ & $\begin{array}{l}\text { Los patios de los } \\
\text { lotes y los espacios } \\
\text { domésticos podrían } \\
\text { reducirse, aunque se } \\
\text { podría aumentar la } \\
\text { convivencia familiar } \\
\text { al perderse menos } \\
\text { tiempo circulando por } \\
\text { el medio urbano. }\end{array}$ \\
\hline $\begin{array}{c}\text { Influencias sobre la } \\
\text { salud general, física y } \\
\text { mental }\end{array}$ & $\begin{array}{l}\text { Considerada } \\
\text { negativa, pero } \\
\text { ambigua }\end{array}$ & $\begin{array}{l}\text { No consen- } \\
\text { sual }\end{array}$ & $\begin{array}{l}\text { Freemann (1992); } \\
\text { McLaren (1992) }\end{array}$ & $\begin{array}{l}\text { Aunque las enferme- } \\
\text { dades respiratorias } \\
\text { son más comunes, hay } \\
\text { otras compensaciones: } \\
\text { se camina más y se re- } \\
\text { duce el sedentarismo. }\end{array}$ \\
\hline Reducción del crimen & Positiva & $\begin{array}{l}\text { No to- } \\
\text { talmente } \\
\text { consensual }\end{array}$ & $\begin{array}{l}\text { Elkin et al. (1991); } \\
\text { Petherick (1991) }\end{array}$ & $\begin{array}{c}\text { La proximidad social } \\
\text { y la revalorización de } \\
\text { los espacios públicos } \\
\text { como lugares de en- } \\
\text { cuentro son aspectos } \\
\text { positivos. }\end{array}$ \\
\hline
\end{tabular}

Fuente: Adaptación de los autores a partir de Burton (2001). 
Figura 13. Energía y consumo en las ciudades: Metabolismo urbano lineal (de las ciudades actuales) y Circular (de las ciudades sostenibles) Fuente: Silva (201I) U-Habitat (2008, p. 156)

Finalmente, la sostenibilidad urbana interesa todos los criterios discutidos en las teorías urbanas contemporáneas que tienen en cuenta las condicionantes sociales, económicas y ambientales $y$, a su vez determinan en la compacidad urbana la mejor relación entre costo, beneficio y convivencia urbana. Conceptualmente, las ciudades sostenibles deben cumplir con criterios definidos por sistemas urbanos de metabolismo circular, en el cual la información, la energía y los materiales (que ingresan al sistema urbano $\mathrm{x}$ dependencia al sistema-entorno) son reciclados o reaprovechados por retroalimentación sistémica, produciendo mayor índice de neguentropía (entropía negativa), con menos residuos y contaminación (salidas de los sistemas urbanos minimizados) (figura I3).

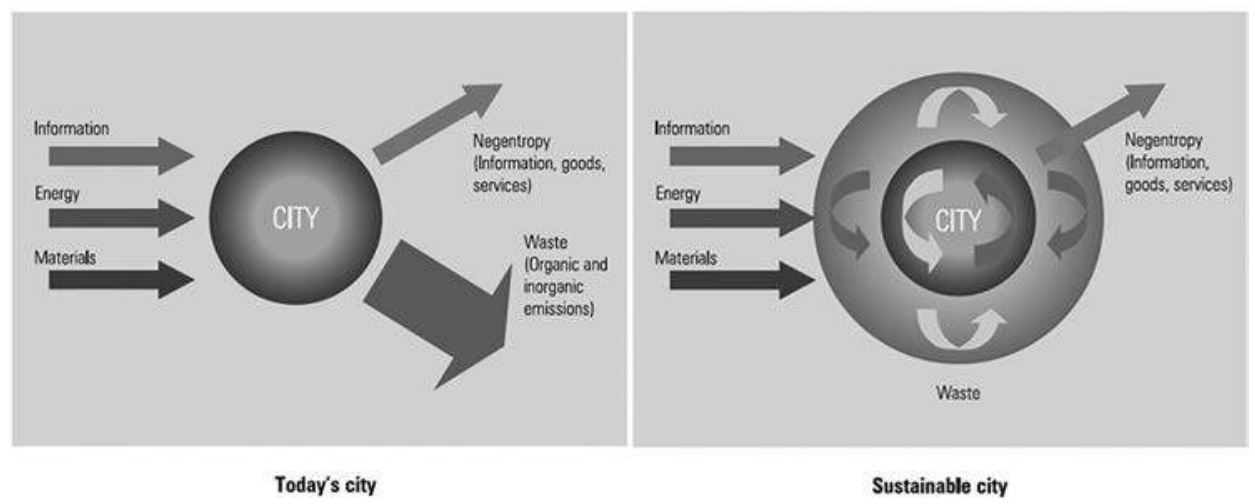

CONSIDERACIONES FINALES

Este texto, aunque no pueda dar la respuesta definitiva sobre la ventaja de un sistema urbano compacto sobre el disperso, desde el punto de vista ambiental, social y económico, contribuye a una mejor visibilidad y realismo en la percepción de la calidad ambiental y de la vida urbana a partir de criterios científicos comprobados por diversas investigaciones en ámbito internacional. Además, ofrece una contribución para desmitificar la asociación que se hace comúnmente ente la cualidad ambiental y la presencia de vacíos urbanos, por lo general habitual en una estructura dispersa, ya que se toman en cuenta diferentes impactos y costos derivados de un elevado consumo energético, de recursos, de infraestructura y mantenimiento.

Según lo discutido, en la ciudad dispersa existen muchos vacíos urbanos, no tratados en la mayoría de los casos, o terrenos privados infrautilizados (bajo especulación). Asimismo, el impulso que se da a la dispersión disminuye la presión de ocupación sobre las áreas vacías ya urbanizadas (particularmente las de capital privado) por lo que se alienta la dispersión hacia nuevas áreas que serán valorizadas por inversiones financiadas con capital público. Por tanto, además de ser más costosa, la ciudad dispersa establece un sistema de transferencias de costos de urbanización hacia el Estado mientras que el sector inmobiliario adquiere grandes ganancias debido a la valorización del suelo, ya sea en las áreas centrales como en las periurbanas, estas últimas más económicas pero que finalmente se valorizan considerablemente por las acciones de ocupación y las inversiones públicas.

Muchos estudios demuestran que, frente a la existencia de inmuebles vacíos o subutilizados en las áreas centrales de las ciudades brasileñas, no sería necesaria la expansión urbana hacia nuevas áreas, pues el número de inmuebles o terrenos vacíos son capaces de satisfacer la demanda habitacional y de crecimiento demográfico con oportunas políticas de ocupación del suelo, bien planificadas y consolidadas a partir de un diseño más cohesivo en términos morfológicos. 
Por su parte, en la ciudad compacta, aunque presentes en menor cantidad, los espacios libres y las áreas verdes, al ser dimensionados en forma más adecuada y viable, pueden ser oportunamente tratados y mejorar el encuentro ciudadano, la cohesión social y la habitabilidad, ya que de hecho podrían ser utilizados por un mayor número de personas. El espacio público es también un elemento de definición para la urbanización y la vida colectiva de la comunidad, ya que su valorización, dimensionamiento y adecuada proporción, asociado a equipamientos urbanos funcionales y accesibles, pueden cambiar positivamente la relación de cercanía a un sector o barrio de la ciudad.

Los aspectos más consensuados en favor de la ciudad compacta son los que se refieren a la accesibilidad, por la mejor proximidad que dichas estructuras permiten y por la mayor densidad, lo que posibilita sistemas de transporte más eficientes, reduciendo el uso de sistemas de transporte individual, ahorrando sensiblemente espacios y equipamientos. Así, la reducción de los costos en los sistemas modales y en los desplazamientos per cápita, inherentes a un menor consumo de combustibles fósiles (cada vez más caros y raros) y a menores índices de emisión de gases, se convierten en puntos fuertes en favor de una política nacional de compactación urbana.

Los equipamientos públicos necesarios podrían ser más completos, ya que serían capaces de atender a más personas mediante una accesibilidad facilitada. Por ejemplo, las escuelas podrían estar en un radio de atención ideal ( $<500 \mathrm{~m}$ de distancia) y podrían, por el número de usuarios, ser mucho más eficientes al contar con laboratorios, bibliotecas, equipos deportivos, implementados con menores costos de mantenimiento, etc.

Como se expuso, a pesar de que en algunos casos, los indicadores cuantitativos- cualitativos de un modelo más expansivo puedan parecer mejores por la cantidad de espacio disponible (área verde per cápita, por ejemplo), por otro lado, su efectiva utilización y su eficiencia de uso, se verifica mejor en ciudades más compactas, ya sea por la mejor distribución espacial y accesibilidad o por un dimensionamiento más apropiado, lo que optimiza su potencial de utilización, debido a una mejor accesibilidad y equidad en la distribución social dentro del conjunto de la estructura urbana.

De esta manera, se puede afirmar que la ciudad compacta puede ser más verde, en el sentido ecológico, que la ciudad difusa, aunque con un índice cuantitativo (superficie verde) menor. En efecto, se presenta como una estructura más cohesiva y con un funcionamiento sistémico más armónico, de mejor sinergia y menor entropía, ya que puede además ofrecer una adecuada red de áreas verdes con dimensiones más reducidas pero más eficientes, adecuadas y cualitativamente mejores, de uso efectivo y con una posibilidad de consolidación más viable que la ofrecida por una estructura urbana difusa (de baja densidad ocupacional).

La reducción de la necesidad de áreas para automóviles y sistemas viales, en los espacios públicos, consiente además un mayor destino de las mismas a la arborización y a las áreas verdes, permitiendo un mejor contacto de la población con la arborización y la reocupación de los espacios, antes dedicados al tráfico vehicular, por espacios de recreación, encuentro social y ocio.

Por último, la idea de sentido de lugar y de pertenencia de las personas es mucho más fuerte y recurrente en ciudades más compactas, como se verifica en las antiguas ciudades medievales o en el oriente medio. Por lo general, los espacios más utilizados por las personas son aquellos con una adecuada escala humana, que promueve el encuentro entre vecinos, valiéndose de bancos, tableros de ajedrez o damas, o simplemente la calle que permite 
la contemplación del paisaje o el intercambio ciudadano. En otras palabras, la vida urbana ligada al genius loci, o sea, al "espíritu del lugar", y de los espacios públicos. Y esa calidad solo es posible cuando se promueve el encuentro de personas en espacios más compactos y ricos en diversidad ocupacional y cultural.

Pero planear ciudades sostenibles tiene que ver con un cambio cultural colectivo y de planificación urbana y regional a partir de la técnica y del conocimiento, en el cual nuevos hábitos urbanos y cívicos deben ser interpretados o promovidos por espacios de calidad, culturalmente más complejos y densos. Así, la información y la educación se convierten en herramientas vitales en este proceso de difusión del conocimiento y de la promoción de "ciudades inteligentes", tanto a nivel de complejidad, tecnología y difusión cultural, como de acceso de sus habitantes a las nuevas oportunidades derivadas de las ganancias educativas, de la comunidad y de las manifestaciones de la cultura urbana y de la técnica.

De este modo, las ganancias socioeconómicas y ambientales tienden a acentuarse a lo largo del tiempo, preservándose por la compacidad y por las áreas naturales del entorno urbano, así como por la reducción de los elementos exógenos de entrada en los sistemas urbanos (energía, recursos, materiales y productos), así como reducción de los impactos ambientales (menos emisión de gases contaminantes, menos residuos, menos consumo del suelo rural), mediante la promoción de tecnologías verdes y sistemas cíclicos de reaprovechamiento material. Son estas las premisas esenciales de un urbanismo más sostenible

y de un metabolismo circular para las ciudades brasileñas del futuro u otras ciudades), las cuales no deben ser necesariamente nuevas ciudades sino ciudades rehabilitadas para albergar una mixtura de nuevos usos en los espacios ya consolidados de la ciudad, en muchos casos, subutilizados.

\section{REFERENCIAS}

Bochet, B., Gay, J-B \& Pini, G. (2003). La ville dense et durable: un modèle européen pour la ville? Revue "Vues sur la ville" - Observatoire Universitaire de la Ville et du Développement Durable.

Burton, E. (200I). The compact city and social justice in Annals of Housing Studies Association Spring Conference Housing, Environment and Sustainability. York: University of York.

Claval, P. (I98I). La logique des villes. Paris: Ed. Litec.

Claval, P. (2000). Reflexions sur la centralité. Cahiers de Géographie au Québec, 44, 123.

Edwards, B. (2005). O guia básico para a sustentabilidade. Barcelona: Gustavo Gili.

Ghorra-Gobin, C. (1998). La ville américaine: espace et société. Paris: Nathan.

Ghorra-Gobin, C. (200I). Les éspaces publics, capital social, 76(I), 05-II. Lyon: Geocarrefour.

Harvey, D. (1980). A Justiça Social e a Cidade. Tradução: Armando Corrêa da Silva, São Paulo: Hucitec.

Haughley, R. (2005). Higher development density: myth and fact. Los Ángeles: Urban Land Institute - University Publications.

Juhnke, K. (1968). A eficiência das ferrovias no transporte metropolitano. Universidade de Bonn. São Paulo: Edgard Blücher. 
Kenworthy, J. et al. (1999). An international sourcebook of automobile dependence in cities Denver: University Press of Colorado.

Levy, J. (1994). Le tournant géographique Paris: Belin.

Maignant, G. (2004). Compacité et forme urbaine, une analyse environnementale dans la perspective d'un développement urbain durable. Publication de Recherche UMR 60I2, CNRS.

Mascaró, J. L. \& Yoshinaga, M. (2005). Infra-estrutura urbana. Porto Alegre: Masquatro Editora.

Mascaró, J. L. (2004). O custo das decisões arquitetônicas. (3a. edição). Porto Alegre: Masquatro Editora.

Medeiros, M.D.L, Mangueira, F.G.N., Silva, G.J.A., Silveira, J.A.R. (20I6).Vila Mocó: uma experiência em projeto de habitação de interesse social na cidade de Itaporanga-PB. João Pessoa: Universidade Federal da Paraíba.

Newton, P. (2000). Urban form and environmental performance. In Jenks, M. et al. Achieving a sustainable urban form. New York: Spon.

Newman, P. \& Kenworthy. (1996). Formes de la ville et transports: vers un nouvel urbanisme. Cahiers de L'I.A.U.R.I.F. no. II4-II5.

Newman, P. \& Kenworthy. (1999). Sustainability and cities: over-coming automobile dependence. London: Island Press.

Ribeiro, E. L. (2006). Cidades (in) sustentáveis - Reflexões e busca de modelos urbanos de menor entropia. João Pessoa: Editora Universitária / Casa do Livro.

Ribeiro, E. L. (2009). Transformations urbaines récentes en villes de taille moyenne en France et au Brésil dans le contexte de la globalisatio. Lyon-France: EVS-EDU - INSA - Lyon.

Ribeiro, E. L. \& Oashi, T. G. (20I0). Princípios de compactação urbana e qualidade de provimentos e de vida urbana. João Pessoa: PRPG/UFPB - Relatório PIBIC.

Ribeiro, E. L. \& Cop, S. G. (20I0). Princípios de compactação urbana e qualidade ambiental urbana. João Pessoa: PRPG/UFPB - Relatório PIBIC.

Ribeiro, E. L. Mousset, J. A. \& Mousset, P. (20I I). L'inefficacité de l'espace public hétéronome dans la ville moderne et contemporaine. Annales du Seminaire "La ville Conviviale - INSA - Lyon - France.

Rogers, R. (1997). Cities for a small planet. London: Paperback.

Rueda, S. P. (1999). Modelos e indicadores para ciudades más sostenibles: taller sobre indicadores de huella de calidad ambiental. Barcelona: Fundación Forum Ambiental / Departament de Medi Ambient de la Generalitat de Catalunya.

Silva, G. J. A. da. (20I I). Cidades sustentáveis: uma nova condição urbana. Estudo de Caso: Cuiabá-MT. Tese de Doutorado (Arquitetura e Urbanismo). Brasília-DF: PPG-FAU-UnB.

Simmonds, D. \& Coombe, D. (2000). The transport implications of alternative urban forms. In Jenks, M. et al. Achieving a sustainable urban form. New York: Spon.

Virilio, P. (1987). Cité, miroir, agonie. Les Annales de la recherche urbaine, no. 34. Paris. 